\title{
O Complexo Juiz de Fora na região de Três Rios (RJ): litogeoquímica, geocronologia U-Pb (LA-ICPMS) e geoquímica isotópica de $\mathrm{Nd}$ e $\mathrm{Sr}$
}

\author{
Jefferson Lima Fernandes André ${ }^{1}$, Claudia Sayão Valladares ${ }^{2} \&$ Beatriz Paschoal Duarte $^{2}$
}

\begin{abstract}
Resumo O Complexo Juiz de Fora na região de Três Rios (RJ) é constituído por uma ampla variedade composicional, tendo protólitos de composição granítica a rochas de composição básica. Com base em estudos litogeoquímicos, pode-se subdividir essa unidade em quatro conjuntos: (i) calcioalcalino de alto-K, (ii) calcioalcalino de médio-K, (iii) toleítico e (iv) alcalino. Pela análise geocronológica (LA-ICPMS, U-Pb em zircão), foram obtidas: idades paleoproterozóicas para a cristalização de um ortognaisse félsico do conjunto calcioalcalino de médio-K, interpretada como idade de cristalização do protólito ígneo; e idades neoproterozóicas $(615,9 \pm 6.4$ Ma e 589,1 $\pm 5 \mathrm{Ma})$ em um ortogranulito máfico do conjunto tolético, interpretadas como sendo idades de metamorfismo. A idade modelo de $\mathrm{Nd}(2,37 \mathrm{Ga})$, associada aos dados de geocronológicos U-Pb e litogeoquímicos, baliza a hipótese do conjunto calcioalcalino de médio-K representar rochas de um arco magmático juvenil. A análise isotópica de $\mathrm{Nd}$ e $\mathrm{Sr}$, em conjunto com a litogeoquímica, sugere que a série toleítica do Complexo Juiz de Fora da região estudada foi gerada em ambiente de fundo oceânico a partir de uma fonte depletada com alguma contribuição de uma fonte enriquecida.
\end{abstract}

Palavras-chave: Complexo Juiz de Fora, litogeoquímica, geocronologia U-Pb (La-ICPMS), geoquímica isotópica de $\mathrm{Nd}-\mathrm{Sr}$.

\begin{abstract}
The Juiz de Fora Complex in the region of Três Rios (RJ): lithogeochemistry, U-Pb geochronology (LA-ICPMS) and Nd-Sr isotopic geochemistry. The Juiz de Fora Complex, in the region of Três Rios (Rio de Janeiro), consists of rocks with a wide range of composition, from granitic to basic terms. Based on lithogeochemical studies, it was possible to subdivide this unit into four associations: (i) high-K calcalkaline, (ii) medium-K calc-alkaline, (iii) tholeiitic and (iv) alkaline. Geochronological analysis (LA-ICPMS, $\mathrm{U}-\mathrm{Pb}$ on zircon) yielded: paleoproterozoic ages for the cristalization of a felsic orthogneiss from the medium$\mathrm{K}$ calc-alkaline group; and neoproterozoic ages (615.9 $\pm 6.4 \mathrm{Ma}$ and 589.1 $\pm 5 \mathrm{Ma})$ from a mafic orthogranulite of the tholeitic group, which were interpreted as metamorphic ages. Nd model age (2.37 Ga), U-Pb and lithogeochemical data indicate that the medium-K calc-alkaline group represents rocks of a paleoproterozoic juvenile magmatic arc. The $\mathrm{Nd}$ and $\mathrm{Sr}$ isotopic geochemistry together with lithogeochemistry suggest that the tholeitic group of the JFC of the studied region was generated in an ocean floor environment, from a depleted source with some contribution from an enriched source.
\end{abstract}

Keywords: Juiz de Fora Complex, lithogeochemistry, U-Pb geochronological analysis (LA-ICPMS), isotopic geochemistry of Nd-Sr.

INTRODUÇÃO O artigo apresentado visa estudar a evolução geológica dos ortogranulitos da região de Três Rios (RJ) que, segundo Heilbron et al. (2004), fazem parte do embasamento paleoproterozóico (pré-1,8 $\mathrm{Ga}$ ) do Terreno Ocidental do Orógeno Ribeira, denominado de Complexo Juiz de Fora (Fig. 1). O presente trabalho tem como base a utilização da litogeoquímica, geocronologia $\mathrm{U}-\mathrm{Pb}$ e geoquímica isotópica de $\mathrm{Nd} \mathrm{e} \mathrm{Sr}$.

O conjunto estudado se posiciona em uma zona de cisalhamento gerada nos estágios finais da formação do Orógeno Ribeira, conhecida como lineamento de Além Paraíba (Almeida et al. 1975) ou Zona de Cisalhamento do Rio Paraíba do Sul (Dayan \& Keller, 1989). Por terem sido totalmente deformadas, as texturas e re- lações originais foram obliteradas, o que dificulta o entendimento das relações de contato dos litotipos. Com base nas ferramentas utilizadas, espera-se contribuir com estas discussões e também correlacionar e comparar os resultados àqueles publicados na literatura para os ortogranulitos do Complexo Juiz de Fora. (Fig. 1).

CONTEXTO GEOLÓGICO A terminologia Série Juiz de Fora foi introduzida por Ebert (1955) que originalmente usou-a para designar paragranulitos da porção interna de uma calha geossinclinal de idade assíntica, cujo eixo se encontrava junto ao rio Paraíba do Sul. Ebert (1968) e Delhal et al. (1969) denominaram o pacote litológico de Grupo Paraíba e Formação

1 - UERJ, Universidade do Estado do Rio de Janeiro, Faculdade de Geologia, Mestre em Ciências pelo Programa de Pós-graduação em Análise de Bacias e Faixas Móveis, Rio de Janeiro (RJ), Brasil. E-mail: jeffersonlfandre@hotmail.com

2 - UERJ, Universidade do Estado do Rio de Janeiro, Faculdade de Geologia, Departamento de Geologia Regional e Geotectônica, Rio de Janeiro (RJ), Brasil. E-mail: vallada@uerj.br, biapasch@uerj.br 


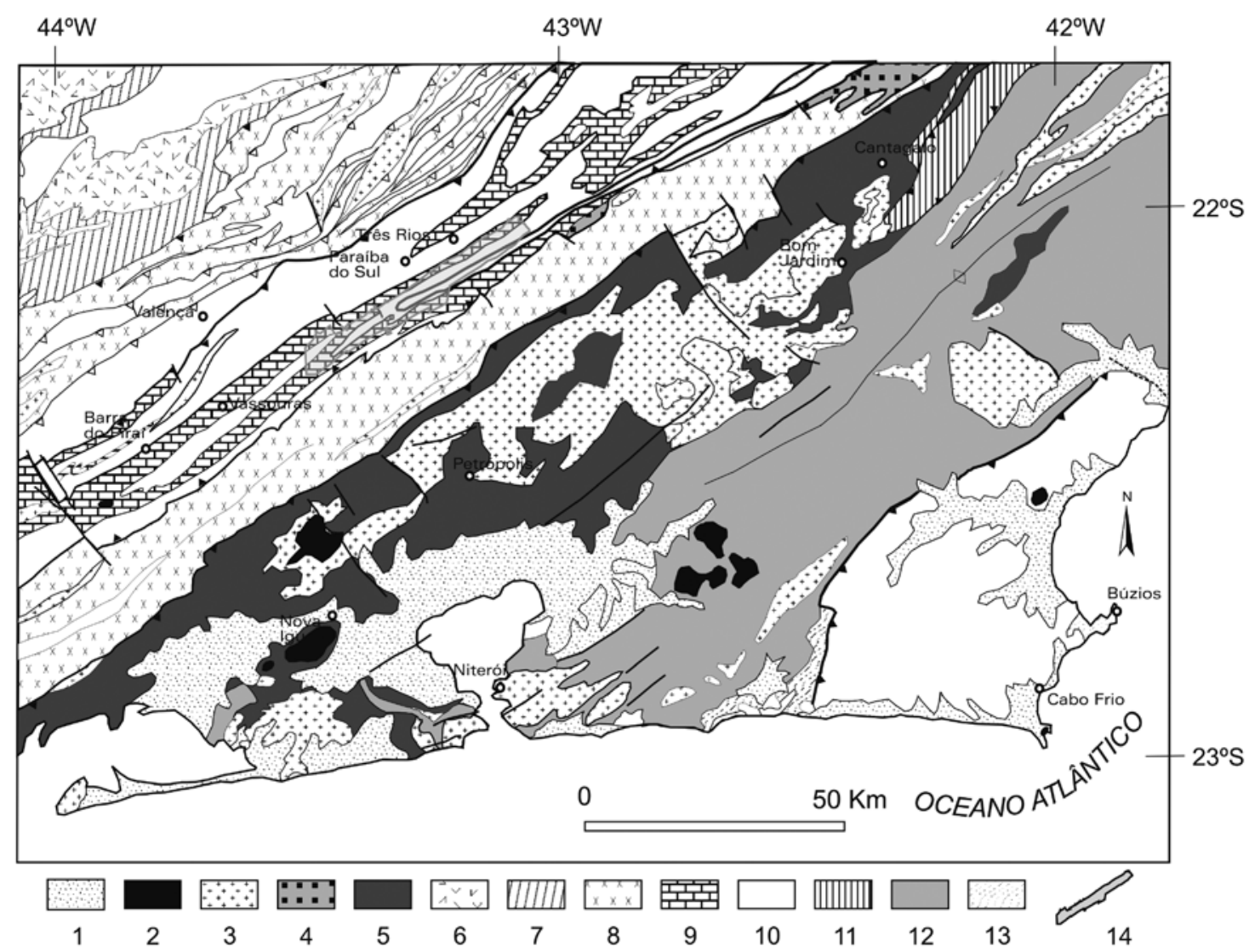

Figura 1 - Mapa Geológico simplificado do Orógeno Ribeira, compilado de Heilbron et al. (2004). Legendas: 1 - Cobertura Terciária e Quaternária; 2 - Rochas alcalinas; 3 Granitóides brasilianos sin-a-pós-colisionais; 4 - Suites Anta e São Primo ; 5 - Arco magmático Rio Negro ; 6 a 9 - Seqüência metassedimentar pós-1.8 Ga do Terreno Ocidental; 6 a 7 - Megasseqüência Andrelandia , 6 - Seqüência Rio Turvo , 7 - Seqüência Carrancas ; 8 -Fácies Distais da Megasseqüência Andrelândia no Domínio Juiz de Fora; 9 - Grupo Paraíba do Sul ; 10 - Rochas do embasamento pré-1,8 Ga; 11 a 12 - Seqüencia metassedimentar pós-1,8 Ga do Terreno Oriental -1 1-Domínio Italva; 12 - Domínio Costeiro; 13 - Seqüência metassedimentar pós-1,8 Ga do Terreno Cabo Frio (Sucessões Búzios e Palmital); 14 - Area de estudo apresentada na figura 2.

Paraíba do Sul, respectivamente, estando aí agrupadas as Séries Juiz de Fora e Paraíba de Ebert (1955). Cordani et al. (1973) separaram esse conjunto em Formações Juiz de Fora e Paraíba do Sul, apesar de ressaltarem a grande semelhança petrológica entre elas.

Oliveira (1983) agrupou as seqüências gnáissicas granulíticas das Séries Juiz de Fora e Paraíba de Ebert sob a denominação de Complexo Juiz de Fora. Este autor individualizou a Faixa Juiz de Fora, com rochas charnockíticas e granulíticas predominantemente, e a Faixa Paraíba do Sul, com migmatitos bandados, anfibolitos, quartzitos e rochas calcissilicáticas.

Barbosa \& Grossi Sad (1983) propuseram a designação de Complexo Juiz de Fora para substituir a série homônima de Ebert, vislumbrando a necessidade de uma definição mais abrangente. Definiram o Complexo Juiz de Fora como uma associação de duas unidades litológicas, intimamente relacionadas: (i) Unidade Comendador Venâncio, na qual predomina a seqüência charnockítica, e (ii) Unidade Raposo que inclui produtos retrometamórficos dos granulitos da Unidade Comedador Venâncio. Os autores também definiram a Unidade Itaperuna, mas não a integraram como parte do complexo em questão.

Machado Filho et al. (1983) dividiram as rochas do Complexo Juiz de Fora, tomando como base parâmetros petrográficos, e sugeriram a subdivisão em duas unidades: Unidade magmática (ortogranulitos e ortogranulitos diaftoréicos) e Unidade metassedimentar (paragranulitos, paragranulitos diaftoréicos e kinzigitos).

Silva et al. (2002), com base em datação U-Pb (SHRIMP) em zircões, obtiveram idades de $2985 \pm 17$ Ga para cristalização e de $2856 \pm 44$ Ga para o metamorfismo de alto grau no Complexo Juiz de Fora. Outros autores sugerem que as idades paleoproterozóicas representam idades de cristalização dos protólitos dos ortogranulitos, ressaltando a ausência de zircões herdados. Neste sentido, Machado et al. (1996a) obtiveram 


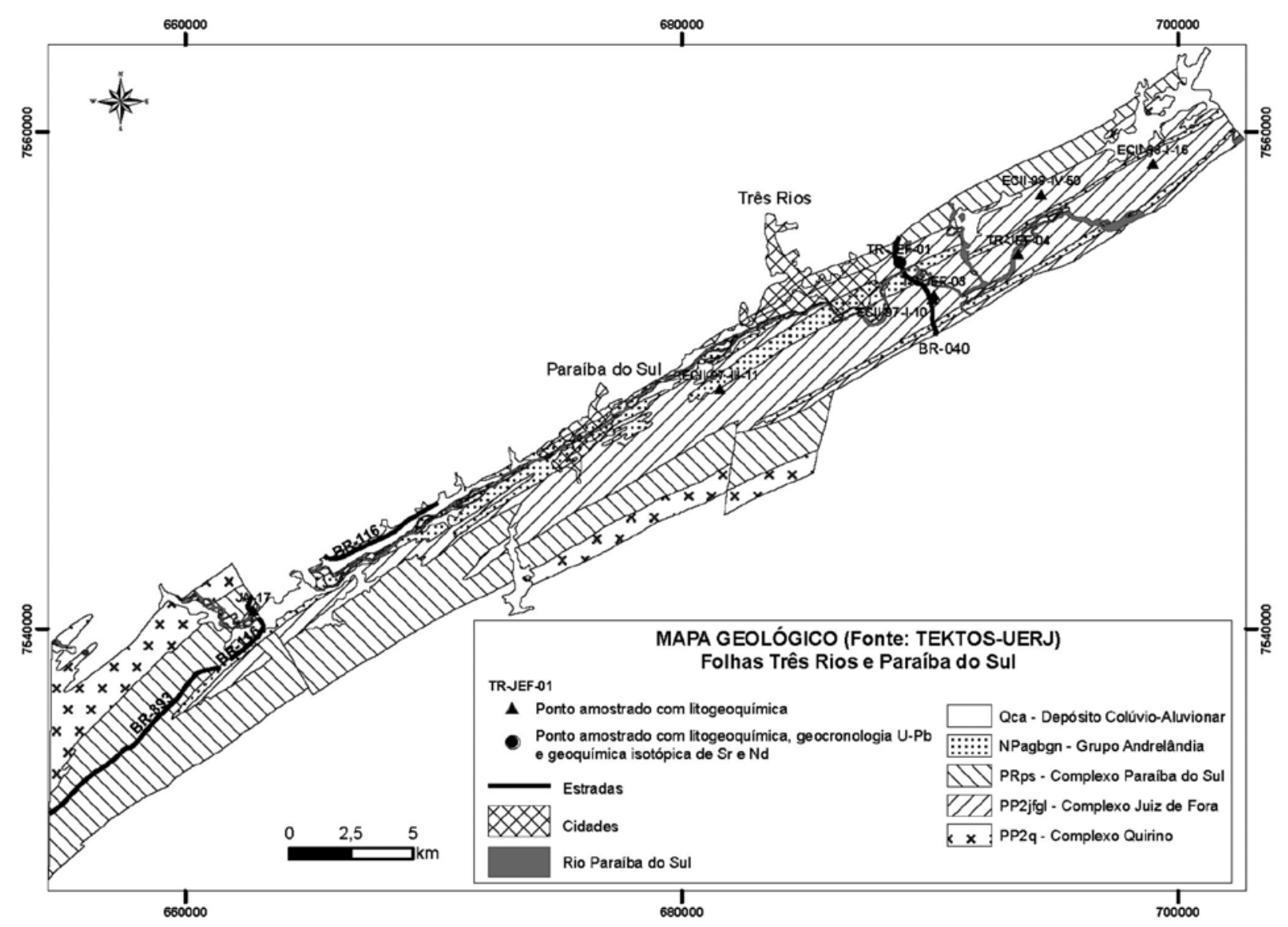

Figura 2 - Mapa geológico local e de localização dos pontos amostrados. Fonte: Grupo TEKTOSUERJ, Folha Três Rios (1:100.000), projeto PRONAGEO-2009, convênio CPRM-UERJ.

idades $\mathrm{U}-\mathrm{Pb}$ convencional em zircão representadas por intercepto superior a $2134 \mathrm{Ma}$, interpretadas como idade de cristalização de protólitos calcioalcalinos. Da mesma forma, Heilbron et al. (2001) obtiveram dados U-Pb em zircão por LA-ICPMS de 2,14 e 2,07 Ga (em ortogranulitos graníticos calcioalcalinos) e $2,4 \mathrm{Ga}$ e $1,7 \mathrm{Ga}$ (em ortogranulitos básicos toleíticos e alcalinos, respectivamente) interpretadas como idades de cristalização dos protólitos. Fischel et al. (1998) obtiveram dados isotópicos Sm-Nd para rochas do Complexo Juiz de Fora ocorrentes na região de Abre Campo-Manhuaçu (MG), obtendo idades modelo $\mathrm{T}_{\mathrm{DM}}(\mathrm{Sm}-\mathrm{Nd})$ correspondentes ao Paleoproterozóico $(2,22-2,13 \mathrm{Ga})$, suportando uma origem juvenil paleoproterozóica para as rochas deste complexo, hipótese sustentada por Ragatky et al. (1999).

No atual estado do conhecimento, a associação litológica do embasamento no Domínio Tectônico Juiz de Fora do Terreno Ocidental é representada por um conjunto de ortogranulitos graníticos a básicos aqui denominado Complexo Juiz de Fora (Heilbron et al. 1998, Heilbron et al. 2004).

MÉTODOS ANALÍTICOS As análises químicas foram efetuadas por ICP-AES (inductively coupled plasma-atomic emmission spectrometry) e ICP-MS (inductively coupled plasma-mass spectrometry), após fusão, no
Activation Laboratories, ACTLABS, no Canadá.

A preparação das amostras para geocronologia $\mathrm{U}-\mathrm{Pb}$, realizada do Laboratório Geológico de Processamento de Amostras (LGPA) da Faculdade de Geologia da Universidade do Estado do Rio de Janeiro, seguiu os procedimentos limpos padrão descritos por Machado et al. (1996b), incluindo britagem, concentração de minerais pesados por bateamento manual e separação por susceptibilidade magnética. O concentrado final de zircão obtido foi separado em frações para e diamagnéticas. A seleção dos cristais, preferencialmente das frações diamagnéticas, foi realizada manualmente sob lupa binocular, selecionando grãos de todas as tipologias encontradas, com tamanho mínimo de 100 mícron, e evitando, quando possível, aqueles com inclusões e fraturas. As análises geocronológicas U-Pb em zircão foram realizadas no Laboratório de Geocronologia da Universidade de Brasília pelo método LA-MC-ICPMS. Os procedimentos analíticos e os métodos utilizados na redução de dados adotados por aquela instituição podem ser obtidos em Buhn et al. (2009).

Para as análises isotópicas em rocha total de Sm-Nd e Sr, utilizou-se um spike enriquecido em ${ }^{149} \mathrm{Sm} /{ }^{150} \mathrm{Nd}(\mathrm{KU} 2 \mathrm{G})$ e, tendo as amostras sido digeridas em $\mathrm{HF}-\mathrm{HNO}_{3}$ concentrado em bombas de teflon revestidas com jaqueta de aço inoxidável a $180-190^{\circ} \mathrm{C}$ 
por 3 dias. Após completa dissolução as amostras foram evaporadas até a secura e redissolvidas em $\mathrm{HCl} 6 \mathrm{~N} . \mathrm{Sr}$ e ETR foram separados utilizando-se colunas padrão de troca catiônica em resina AG-50WX8, 200-400 mesh em $\mathrm{HCl} 2,5 \mathrm{~N}$ para $\mathrm{Rb}$ e $\mathrm{Sr}$ e $\mathrm{HCl} 6 \mathrm{~N}$ para ETR. A segunda etapa realiza-se em colunas empacotadas com Ln Spec, com a finalidade de separar o $\mathrm{Sm}$ e o $\mathrm{Nd}$ do conjunto das terras raras, também em meio ácido $(\mathrm{HCl}$ $0,18 \mathrm{~N}$ para $\mathrm{Nd}$ e $0,5 \mathrm{~N}$ para $\mathrm{Sm}) . \mathrm{Sr}, \mathrm{Sm}$ e $\mathrm{Nd}$ foram depositados em filamento duplo de Re. As análises isotópicas de $\mathrm{Nd}$ e $\mathrm{Sr}$ foram efetuadas em Espectrômetro de Massa Finnigan Triton-TI (equipado com detectores Daly e Faraday) do Laboratório de Geocronologia e Isótopos Radiogênicos (LAGIR) da Faculdade de Geologia da Universidade do Estado do Rio de Janeiro. Os procedimentos analíticos utilizados por este laboratório podem ser obtidos em Valeriano et al. (2009).

\section{FEICÕES DE CAMPO E CARACTERÍSTICAS}

PETROGRÁFICAS Na Zona de Cisalhamento do Rio Paraíba do Sul na região de Três Rios (RJ) afloram rochas ortogranulíticas do Complexo Juiz de Fora, um granada-biotita gnaisse relacionado a metassedimentos da bacia Andrelândia (Grupo Andrelândia), metassedimentos do Complexo Paraíba do Sul, ortognaisses do Complexo Quirino e pequenos corpos graníticos não mapeáveis na escala do mapa. Todo esse conjunto forma uma faixa estreita (de 4 a $5 \mathrm{~km}$ de largura) de rochas miloníticas de direção NE. Os melhores afloramentos de rochas ortogranulíticas do Complexo Juiz de Fora são encontrados às margens do Rio Paraíba do Sul, em cortes de estrada (como a BR-040) e na Pedreira Tabaiara (ponto TR-JEF-03) (Fig. 2). Estas rochas foram completamente deformadas, tendo sido submetidas a pelo menos três eventos deformacionais e dois eventos metamórficos (Heilbron et al. 2004). Dados disponíveis na literatura indicam que na Zona de Cisalhamento do Rio Paraíba do Sul há evidências de superposição de dois eventos deformacionais associados ao desenvolvimento de zonas de cisalhamento dúcteis (Almeida, 2000) relacionadas, respectivamente, aos eventos de colisão II e III de Heilbron et al. (2004). Ambos os eventos estão relacionados ao desenvolvimento de milonitos e paragêneses retrógradas.

No campo foram definidos três litotipos distintos: ortogranulitos básicos, ortogranulitos intermediários e ortogranulitos ácidos, assim como foi distinguido por Duarte et al. (1997). Essas rochas estão intensamente deformadas e milonitizadas, seus contatos são paralelos e subverticais, o que faz ressaltar uma estrutura bandada, transformando o conjunto esverdeado, aparentemente homogêneo quando fora da zona de cisalhamento, em uma sucessão de bandas brancas e pretas (Fig. 3a). Porém, na Pedreira Tabaiara, é observada uma possível relação de intrusão do litotipo ácido no básico, indicando que o litotipo básico seja mais antigo (Fig. 3b). Já para a rocha intermediária, não foi identificada qualquer relação com os outros litotipos. De uma maneira geral, as três litologias são encontradas no mesmo afloramento.

Em muitos afloramentos, foi diagnosticada condição de metamorfismo em facies granulito pela presença de ortopiroxênio (hiperstênio), encontrado tanto em amostras de mão quanto em lâmina delgada. Porém, feições de retrometamorfismo são bastante comuns em análise microscópica, provavelmente geradas pela implantação de zonas de cisalhamento (associadas às colisões II e III), o que levou, muitas vezes, à obliteração total da paragênese granulítica e transformação de ortogranulitos em ortognaisses e de noritos em ortoanfibolitos sem ortopiroxênio.

Pela análise modal, foi determinado que a unidade estudada possui uma ampla variedade composicional, compreendendo rochas de composição básica (gabróica), intermediária (quartzo-diorítica, tonalítica e quartzo sienítica) e ácida (granítica e granodioritica) (Tab. 1 e Fig. 4).

Os ortogranulitos/ortoanfibolitos de composição gabróica possuem granulometria variando de muito
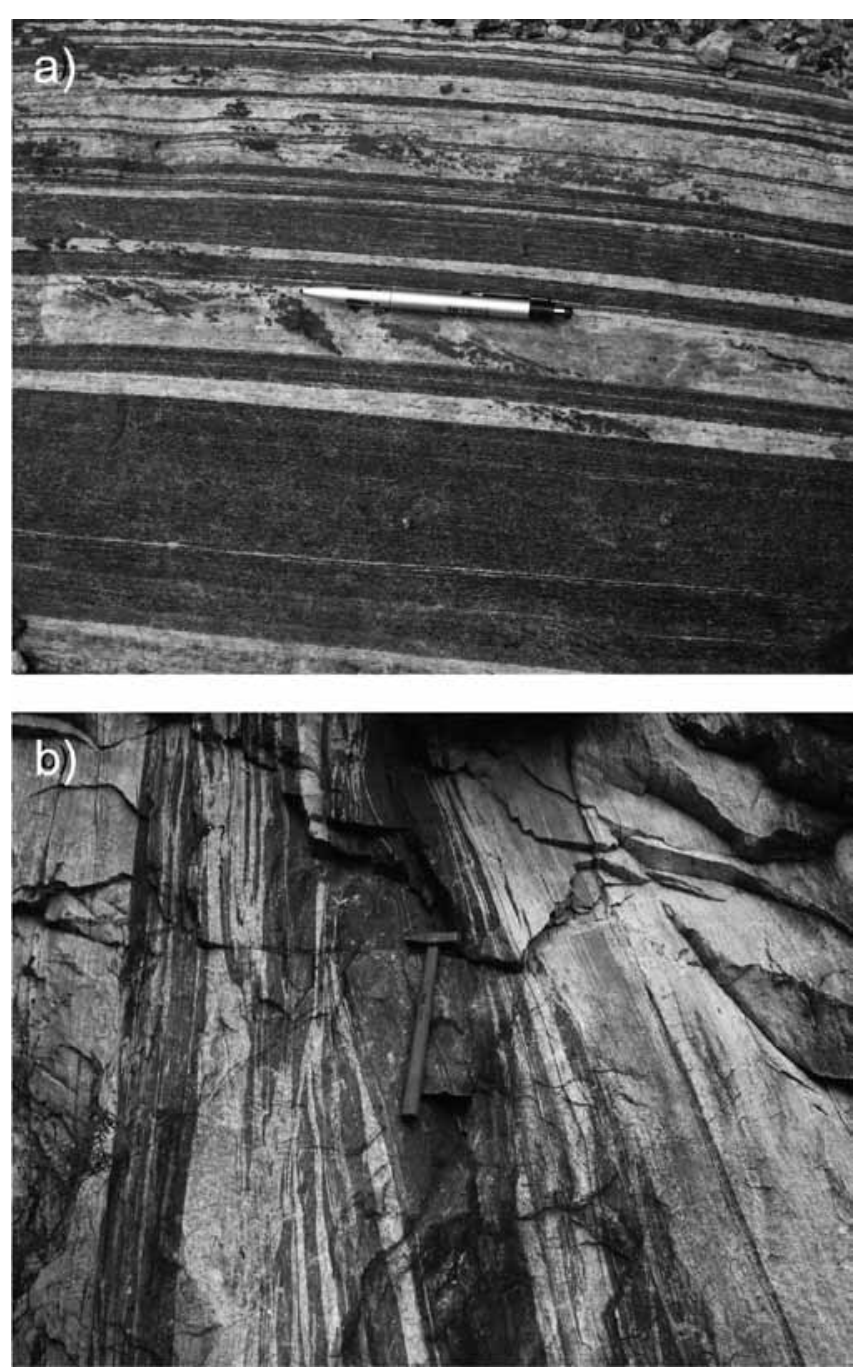

Figura 3 - Relação de campo observada nos ortogranulitos do Complexo Juiz de Fora na Pedreira Tabaiara, Três Rios (RJ): (a) Contato tectônico paralelo entre os litotipos básico e ácido na Zona de Cisalhamento do Rio Paraíba do Sul; (b) Relação de intrusão do litotipo ácido no básico (Ponto TR-JEF-03). 
Tabela 1 - Composição modal (por contagem de pontos) dos ortogranulitos/ortognaisses da região de Três Rios (RJ).

\begin{tabular}{|c|c|c|c|c|c|c|c|c|c|c|c|}
\hline Amostras & $\begin{array}{c}\text { Quartzo } \\
(\%)\end{array}$ & $\begin{array}{c}\text { Plagioclásio } \\
(\%)\end{array}$ & $\begin{array}{c}\text { K-feldspato } \\
(\%)\end{array}$ & $\begin{array}{c}\text { Biotita } \\
(\%)\end{array}$ & $\begin{array}{c}\text { Hornblenda } \\
(\%)\end{array}$ & $\begin{array}{l}\text { Opx } \\
(\%)\end{array}$ & $\begin{array}{l}\text { Cpx } \\
(\%)\end{array}$ & $\begin{array}{c}\text { Minerais } \\
\text { acessórios } \\
(\%)\end{array}$ & $\begin{array}{c}\text { Muscovita } \\
(\%)\end{array}$ & $\begin{array}{c}\text { Granada } \\
(\%)\end{array}$ & $\begin{array}{l}\text { Classificação } \\
\text { do protólito }\end{array}$ \\
\hline TR-JEF-01 & & 45 & & & 30 & 5 & 20 & & & & Basalto \\
\hline TR-JEF-01A & 36,5 & 41 & 16 & 3,5 & & & & 2,7 & & & Granodiorito \\
\hline TR-JEF-01C1 & 35,7 & 41,2 & 1,9 & 9,5 & 1,7 & & & & & & Granodiorito \\
\hline JA-17-JEFA & & 45 & & 15 & 3,9 & & $<1$ & & & & Basalto \\
\hline JA-17-JEFB & & 48 & & 23 & 28 & & & 1 & & & Basalto \\
\hline JA-17-JEFC & 5,2 & 15,2 & 52,1 & 16,9 & 5,7 & & & 3,9 & 0,7 & $<1$ & $\begin{array}{l}\text { Quartzo } \\
\text { sienito }\end{array}$ \\
\hline JA-17-JEFD & 31 & 35,2 & 1,7 & 29,7 & & & & 1,4 & 0,9 & & Tonalito \\
\hline TR-JEF-03A & & 40 & & 5 & 30 & 4 & 20 & 1 & & & Basalto \\
\hline TR-JEF-O3B & 36,7 & 37,5 & 20 & 2,5 & & $<1$ & & 2 & & & Monzogranito \\
\hline TR-JEF-03C & 31,7 & 40,2 & 16,2 & 9 & & 1 & & 1,9 & & & Granodiorito \\
\hline TR-JEF-04A & 26,1 & 21 & 52 & $<1$ & & & & & & & Sienogranito \\
\hline TR-JEF-04B & 43,7 & 33,2 & 17,2 & 4,7 & & $<1$ & & 0,9 & & & Granodiorito \\
\hline TR-JEF-04C & 47,7 & 33,1 & 13,6 & 4 & & 1 & & & & $<1$ & Granodiorito \\
\hline ECII-97-III-11 & & 45 & & 20 & & 20 & 15 & & & & Basalto \\
\hline ECII-98-I-15A & 5,7 & 49,2 & & 5,7 & 4,7 & 27 & 2,7 & 3,5 & & & $\begin{array}{c}\text { Quartzo } \\
\text { diorito/quartzo } \\
\text { gabro } \\
\end{array}$ \\
\hline ECII-98-IV-50 & 5,5 & 55,2 & & 26,5 & 2,2 & 4,2 & 4,7 & 0,7 & & & $\begin{array}{c}\text { Quartzo } \\
\text { diorito/quartzo } \\
\text { gabro } \\
\end{array}$ \\
\hline ECII-97-I-10F & & 44 & & 10 & 8 & 21 & 17 & & & & Basalto \\
\hline ECII-98-I-10 & 36 & 36,1 & 10,2 & 9,7 & 2,5 & 1 & 1 & 2,5 & & & Granodiorito \\
\hline
\end{tabular}

fina a fina e textura granoblástica a nematoblástica. São compostos, em média, essencialmente por clinopiroxênio $(13 \%)$, ortopiroxênio $(8 \%)$, hornblenda $(17 \%)$, biotita $(12 \%)$ e plagioclásio $(44 \%)$, além de minerais acessórios como apatita, opacos e zircão.

Os ortogranulitos de composição quartzo-dioritítica apresentam granulometria variando de fina a média e textura granoblástica. São constituídos, em média, por clinopiroxênio (4\%), ortopiroxênio (16\%), biotita $(16 \%)$, hornblenda (3\%), quartzo $(6 \%)$, plagioclásio $(52 \%)$ e outros minerais como opacos e zircão. Podese observar texturas indicativas de retrometamorfismo entre clinopiroxênio e hornblenda, hornblenda e biotita e ortopiroxênio e biotita.
Apenas uma das rochas analisadas pôde ser classificada como ortognaisses de composição tonalítica. Estas rochas são bandadas e possuem granulometria muito fina a fina, com textura granoblástica e porfiroclastos de plagioclásio e microclina. São compostas, em média, por plagioclásio (35\%), quartzo (31\%), biotita $(30 \%)$ e microclina (2\%). Como acessórios ocorrem zircão, opacos e apatita. A muscovita aparece como mineral secundário, formado a partir do consumo parcial da microclina.

O ortognaisse de composição quartzo-sienítica possui textura granoblástica e granulometria fina. É composto por microclina $(52 \%)$, plagioclásio (15\%), quartzo $(5 \%)$, hornblenda $(6 \%)$, biotita $(17 \%)$, tendo como minerais acessórios granada, opacos e apatita. Retrometa- 


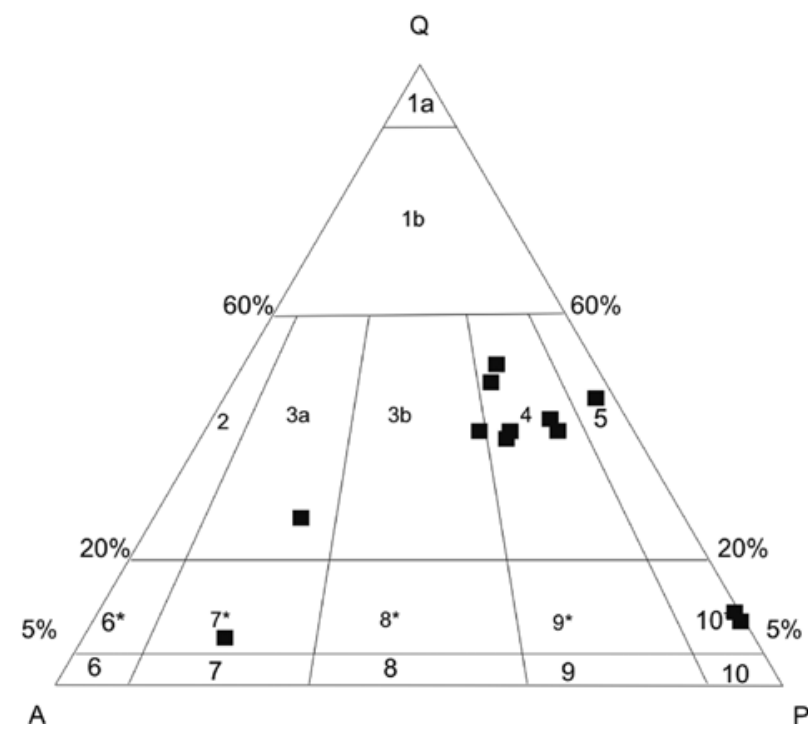

\author{
Legenda \\ 1a - Quartzolito \\ 1b - Granitóide rico em quartzo \\ 2 - Álcali-feldspato-granito \\ 3 - Granito - 3a - sienogranito \\ 4 - Granodiorito \\ 5 - Tonalito \\ 6* - Quartzo-álcali-feldspato \\ $7^{\star}$ - Quartzo-sienito \\ 8* - Quartzo-monzonito \\ 9* - Quartzo-monzodiorito \\ Quartzo-monzogabro \\ 10* - Quartzo-diorito ou Quartzo-gabro \\ 6 - Álcali- Feldspato-sienito \\ 7 - Sienito \\ 8 - Monzonito \\ 9- Monzodiorito ou Monzogabro \\ 10 - Diorito ou Gabro
}

Figura 4 - Diagrama QAP (Streckeisen, 1976) para os ortogranulitos /ortognaisses ácidos e intermediários do Complexo Juiz de Fora da região de Três Rios (RJ).

morfismo é evidenciado pela substituição parcial de hornblenda por biotita e de microclina por muscovita.

Os ortogranulitos/ortognaisses granodioríticos possuem textura milonítica, com matriz quartzo-feldspática e ribbons de quartzo e ortoclásio. São constituídos, em média, essencialmente por quartzo (38\%), plagioclásio (37\%) e ortoclásio (13\%). Dentre os minerais máficos, a biotita ( $9 \%)$ é o mais comum, enquanto que a hornblenda e o ortopiroxênio não ultrapassam, em conjunto, $3 \%$ da constituição dessas rochas. $\mathrm{O}$ ortopiroxênio é encontrado às vezes como pofiroclasto. O retrometamorfismo é evidenciado pela substituição parcial de ortopiroxênio por biotita.

Os ortogranulitos/ortognaisses de composição granítica possuem textura milonítica e são constituídos, em média, essencialmente por quartzo (32\%), plagioclásio (30\%) e K-feldspatos (36\%). Na matriz quartzo-felspática o K-feldspato é a microclina, enquanto que os porfiroclastos são representados por plagioclásio e ortoclásio. Biotita (2\%) é o mineral máfico mais comum e ocorre preferencialmente orientada na matriz da rocha. Ortopiroxênio $(<1 \%)$ também é encontrado em algumas amostras e é comum a ocorrência de biotita em suas bordas.

LITOGEOQUÍMICA Com o intuito de caracterizar geoquimicamente os ortogranulitos/ortognaisses da região Três Rios, foram realizadas 18 análises químicas de rocha total (elementos maiores e traços, incluindo os terras raras), englobando os três tipos petrográficos identificados em campo (Tabs. 2a, 2b). Com base nos resultados da análise petrográfica, foram selecionados como pontos de coleta afloramentos localizados em pedreiras, cortes de estradas e no leito do rio Paraíba do Sul, que continham rochas com a paragênese metamórfica indicativa de facies granulito preservada. $\mathrm{O}$ cuidado na escolha de afloramentos, nos quais a paragênese granulítica estivesse preservada, foi necessário para evitar amostras possivelmente afetadas por retrometamorfismo ou metassomatismo decorrentes da localização em zonas de cisalhamento dúcteis.

Das dezoito amostras selecionadas para geoquímica, 6 são de granulitos máficos de composição gabróica (noritos), 4 são de granulitos/gnaisses intermediários de composição tonalítica a quartzo-diorítica e 8 são de granulitos/gnaisses ácidos de composição granítica a granodiorítica. Os dados litogeoquímicos e petrográficos integrados (Tab. 1) indicam que os noritos compõem rochas básicas $\left(\mathrm{SiO}_{2}\right.$ entre 46,2 e 50,7\%), os ortogranulitos/ortognaisses tonalíticos e quartzodioríticos são rochas intermediárias $\left(\mathrm{SiO}_{2}\right.$ entre 55,9 e $63,3 \%$ ), enquanto que os ortogranulitos/ortognaisses granodioríticos e graníticos constituem rochas ácidas ( $\mathrm{SiO}_{2}$ entre 66,7 e 75,7\%). Valores de LOI menores que 1,58 , com exceção de uma amostra (com 2,2$)$, não mostram problemas ou correlações que possam indicar processos metassomáticos ou intempéricos. $\mathrm{O}$ fechamento das análises variou entre 98,47 e 101,00, sendo considerados razoáveis.

Caracterização química das rochas $\mathrm{O}$ estudo litogeoquímico mostra que as rochas do Complexo Juiz de Fora na região de Três Rios representam quatro séries magmáticas distintas (Fig. 5), intensamente interdigitadas pela tectônica brasiliana, são elas: duas séries cálcioalcalinas, sendo uma de médio-K e outra de alto$\mathrm{K}$; uma série toleítica; e apenas uma amostra de rocha básica de tendência alcalina. As séries calcioalcalinas incluem o conjunto de rochas intermediárias a ácidas, enquanto que as rochas básicas pertencem às séries toleítica e alcalina. Para a classificação das rochas básicas, foram considerados mais relevantes os diagramas de Winchester e Floyd (1977; Figs. 5d e 5e), por se basearem em elementos traços imóveis. Neste sentido das seis amostras básicas investigadas, cinco foram classi- 
Tabela 2 a - Composição química das rochas do Complexo Juiz de Fora da região de Três Rios: elementos maiores (em \% peso).

\begin{tabular}{|c|c|c|c|c|c|c|c|c|c|c|c|c|}
\hline Amostras & $\mathrm{SiO} 2$ & $\mathrm{Al} 2 \mathrm{O} 3$ & $\mathrm{Fe} 2 \mathrm{O} 3(\mathrm{~T})$ & $\mathrm{MnO}$ & $\mathrm{MgO}$ & $\mathrm{CaO}$ & $\mathrm{Na} 2 \mathrm{O}$ & $\mathrm{K} 2 \mathrm{O}$ & $\mathrm{TiO} 2$ & $\mathrm{P} 2 \mathrm{O} 5$ & LOI & Total \\
\hline TR-JEF-03B & 75,72 & 13,43 & 0,87 & 0,012 & 0,11 & 1,24 & 3,57 & 5,02 & 0,063 & 0,02 & 0,58 & 100,6 \\
\hline TR-JEF-04A & 74,82 & 13,71 & 0,59 & 0,009 & 0,02 & 1 & 3,47 & 5,42 & 0,049 & 0,01 & 0,5 & 99,6 \\
\hline TR-JEF-04C & 74,49 & 13,87 & 1,69 & 0,023 & 0,29 & 1,92 & 4,3 & 3,02 & 0,174 & 0,06 & 0,68 & 100,5 \\
\hline TR-JEF-04B & 73,62 & 14,18 & 2,2 & 0,03 & 0,39 & 2,24 & 4,49 & 2,33 & 0,242 & 0,08 & 0,72 & 100,5 \\
\hline TR-JEF-01-C1 & 73,05 & 14,43 & 2,38 & 0,018 & 0,53 & 2,38 & 4,03 & 3,02 & 0,254 & 0,09 & 0,74 & 100,9 \\
\hline TR-JEF-03C & 71,65 & 14,11 & 2,26 & 0,027 & 0,44 & 2,48 & 4,52 & 2,06 & 0,25 & 0,08 & 0,6 & 98,49 \\
\hline TR-JEF-01A & 70,76 & 14,76 & 2,83 & 0,022 & 0,51 & 2,68 & 4,47 & 2,31 & 0,321 & 0,09 & 0,66 & 99,41 \\
\hline ECII-98-I-10 & 67,61 & 15,02 & 3,64 & 0,054 & 1,18 & 3,33 & 4,4 & 2,1 & 0,447 & 0,16 & 0,57 & 98,52 \\
\hline JA-17-JEFC & 63,3 & 15,93 & 5,14 & 0,162 & 0,74 & 2,14 & 3,45 & 5,36 & 0,921 & 0,29 & 1,05 & 98,47 \\
\hline JA-17-JEFD & 62,32 & 16,1 & 5,85 & 0,084 & 2,02 & 3,79 & 4,07 & 2,15 & 0,894 & 0,32 & 1,25 & 98,84 \\
\hline ECII-98-I-15A & 56,34 & 14,18 & 9,68 & 0,155 & 4,76 & 9,25 & 2,84 & 0,43 & 0,655 & 0,08 & 0,14 & 98,51 \\
\hline ECII-98-IV-50 & 55,9 & 15,17 & 11,22 & 0,157 & 5,6 & 4,13 & 3,37 & 2,14 & 1,054 & 0,17 & 1,01 & 99,91 \\
\hline ECII-97-I-10F & 50,7 & 16,45 & 11,81 & 0,161 & 5,41 & 8,96 & 3,73 & 1,1 & 1,132 & 0,1 & 0,76 & 100,3 \\
\hline ECII-97-III-11 & 50,65 & 12,5 & 10,92 & 0,16 & 8,76 & 8,17 & 2,92 & 2,53 & 1,176 & 0,22 & 1,3 & 99,31 \\
\hline JA-17-JEFB & 50,44 & 16,54 & 9,68 & 0,165 & 5,47 & 7,7 & 3,24 & 2,22 & 1,658 & 0,65 & 1,57 & 99,33 \\
\hline TR-JEF-01 & 49,57 & 16,85 & 11,14 & 0,157 & 5,98 & 11,42 & 3,04 & 0,71 & 1,071 & 0,09 & 0,3 & 100,3 \\
\hline JA-17-JEFA & 48,97 & 16,69 & 10,91 & 0,19 & 5,73 & 7,9 & 3,49 & 2,22 & 2,036 & 0,62 & 2,2 & 101 \\
\hline TR-JEF-03A & 46,2 & 15,32 & 11,81 & 0,168 & 8,71 & 9,79 & 3,03 & 1,28 & 0,7 & 0,08 & 1,58 & 98,67 \\
\hline
\end{tabular}

Tabela $2 b$ - Composição química das rochas do Complexo Juiz de Fora da região de Três Rios: elementos traços e elementos terras raras (em ppm).

\begin{tabular}{|c|c|c|c|c|c|c|c|c|c|c|c|c|c|c|c|c|c|c|c|c|c|c|c|c|c|c|c|c|}
\hline Amostras & $\mathrm{V}$ & $\mathrm{Ba}$ & $\mathrm{Sr}$ & $\mathrm{Y}$ & $\mathrm{Zr}$ & $\mathrm{Cr}$ & $\mathrm{Co}_{0}$ & $\mathrm{Ni}$ & $\mathrm{Rb}$ & $\mathrm{Sc}$ & $\mathrm{Cu}$ & $\mathrm{Zn}$ & $\mathrm{Ga}$ & $\mathrm{Nb}$ & $\mathrm{La}$ & $\mathrm{Ce}$ & $\operatorname{Pr}$ & $\mathrm{Nd}$ & $\mathrm{Sm}$ & $\mathrm{Eu}$ & $\mathrm{Gd}$ & $\mathrm{Tb}$ & Dy & Ho & Er & $\mathrm{Tm}$ & $\mathrm{Yb}$ & $\mathrm{Lu}$ \\
\hline TR-JEF-03B & & 197 & 75 & 3 & 68 & $<20$ & 33 & $<20$ & 180 & 2 & $<10$ & $<30$ & 23 & 2 & 14,9 & 26,7 & 2,8 & 10,6 & 2,4 & 0,51 & 1,9 & 0,2 & 0,9 & 0,2 & 0,4 & 0,05 & 0,4 & 0,06 \\
\hline TR-JEF-04A & $<5$ & 296 & 91 & $<2$ & 88 & $<20$ & 35 & $<20$ & 179 & $<1$ & 20 & $<30$ & 20 & $<1$ & 10,4 & 25,5 & 1,97 & 5,7 & 0,9 & 0,55 & 0,5 & $<0.1$ & 0,4 & $<0.1$ & 0,2 & $<0.05$ & 0,2 & 0,04 \\
\hline TR-JEF-04C & 6 & 689 & 186 & 2 & 117 & $<20$ & 38 & $<20$ & 105 & 2 & $<10$ & 40 & 21 & 5 & 19,3 & 35 & 3,94 & 12,5 & 2,3 & 0,7 & 1,7 & 0,2 & 0,9 & 0,1 & 0,3 & $<0.05$ & 0,3 & 0,04 \\
\hline TR-JEF-04B & 17 & 494 & 185 & 4 & 178 & $<20$ & 54 & $<20$ & 91 & 3 & $<10$ & 60 & 22 & 7 & 21,6 & 40,6 & 4,69 & 15 & 2,9 & 0,71 & 2,1 & 0,2 & 1,1 & 0,2 & 0,4 & 0,05 & 0,3 & 0,05 \\
\hline TR-JEF-01-C1 & 20 & 431 & 275 & $<2$ & 133 & $<20$ & 19 & $<20$ & 95 & 3 & 60 & 50 & 20 & 5 & 13,7 & 24,8 & 2,63 & 8,7 & 1,7 & 0,53 & 1,2 & 0,1 & 0,5 & $<0.1$ & 0,2 & $<0.05$ & 0,1 & $<0.04$ \\
\hline TR-JEF-03C & 19 & 397 & 229 & 2 & 175 & $<20$ & 33 & $<20$ & 84 & 3 & 50 & 60 & 21 & 6 & 24 & 40,8 & 4,29 & 13 & 2,2 & 0,81 & 1,6 & 0,2 & 1 & 0,2 & 0,4 & 0,05 & 0,3 & 0,05 \\
\hline TR-JEF-01A & 19 & 298 & 271 & 4 & 182 & $<20$ & 29 & $<20$ & 52 & 3 & $<10$ & 60 & 22 & 6 & 50,2 & 101 & 11,7 & 33,8 & 6 & 0,68 & 3,2 & 0,3 & 1,1 & 0,2 & 0,4 & 0,06 & 0,4 & 0,06 \\
\hline ECII-98-I-10 & 43 & 684 & 421 & 7 & 161 & $<20$ & 31 & $<20$ & 76 & 6 & $<10$ & 90 & 22 & 7 & 26,1 & 51,3 & 6,21 & 20,3 & 3,8 & 1,06 & 2,7 & 0,4 & 1,7 & 0,3 & 0,8 & 0,1 & 0,6 & 0,08 \\
\hline JA-17-JEFC & 41 & 2325 & 292 & 28 & 1075 & 40 & 31 & $<20$ & 178 & 14 & $<10$ & 130 & 21 & 24 & 45,3 & 94,3 & 12,3 & 42,7 & 8,7 & 3,22 & 7,5 & 1 & 5,4 & 1 & 2,8 & 0,39 & 2,4 & 0,37 \\
\hline JA-17-JEFD & 87 & 586 & 317 & 18 & 294 & 30 & 70 & $<20$ & 130 & 11 & $<10$ & 120 & 22 & 13 & 44 & 90,6 & 10,7 & 32,7 & 6,3 & 1,44 & 4,9 & 0,7 & 3,7 & 0,7 & 2 & 0,27 & 1,4 & 0,2 \\
\hline ECII-98-I-15A & 182 & 236 & 301 & 16 & 56 & 220 & 76 & 80 & 12 & 28 & 60 & 80 & 18 & 3 & 5 & 11,6 & 1,71 & 7,4 & 2 & 0,73 & 2,5 & 0,5 & 3,1 & 0,6 & 1,9 & 0,28 & 1,8 & 0,27 \\
\hline ECII-98-IV-50 & 155 & 556 & 447 & 5 & 50 & 140 & 55 & $<20$ & 63 & 14 & 30 & 160 & 24 & 7 & 9,3 & 17,5 & 2,18 & 7,4 & 1,5 & 1,09 & 1,3 & 0,2 & 1,1 & 0,2 & 0,7 & 0,1 & 0,7 & 0,11 \\
\hline ECII-97-I-10F & 284 & 167 & 214 & 29 & 69 & 90 & 57 & $<20$ & 20 & 35 & 40 & 160 & 21 & 7 & 16 & 40,9 & 5,89 & 22,8 & 5,4 & 1,27 & 5,3 & 0,9 & , & 1,1 & 3,2 & 0,45 & 2,8 & 38 \\
\hline ECII-9 & 264 & 565 & 272 & 23 & 118 & 470 & 50 & 100 & 129 & 35 & 200 & 120 & 21 & 9 & 18 & 43 & 5,37 & 22,9 & 5,7 & 1,47 & 5,4 & 0,8 & 4,4 & 0,9 & 2,6 & 0,37 & 2,3 & 0,31 \\
\hline JA-17-JEFB & 206 & 1115 & 521 & 81 & 205 & 4 & 40 & $<20$ & 110 & 29 & 20 & 150 & 23 & 21 & 46,9 & 130 & 20,3 & 78,1 & 18,4 & 2,87 & 15,9 & 2,5 & 14,5 & 2,9 & 4 & 1,2 & 7,3 & 04 \\
\hline TR-JEF-01 & 282 & 29 & 155 & 15 & 51 & 80 & 45 & 30 & 6 & 34 & 60 & 120 & 18 & 3 & 4,2 & 10,7 & 1,62 & 7,5 & 2,1 & 0,92 & 2,5 & 0,4 & 2,8 & 0,6 & 1,8 & 9,26 & 1,6 & 0,25 \\
\hline JA-17. & 221 & 1261 & 764 & 33 & 244 & 50 & 42 & $<20$ & 91 & 24 & 20 & 180 & 21 & 14 & 58,2 & 123 & 15,4 & 47,6 & 9 & 2,71 & 7,3 & 1,1 & 6,1 & 1,2 & 3,4 & 0,5 & 3 & 0,44 \\
\hline TR-JEF-03A & 244 & 190 & 168 & 15 & 28 & 250 & 63 & 220 & 70 & 33 & 20 & 50 & 17 & 3 & 4,7 & 10,2 & 1,48 & 6,3 & 1,7 & 0,73 & 2,3 & 0,4 & 2,9 & 0,6 & 2 & 0,3 & 2 & 0,3 \\
\hline
\end{tabular}


a)

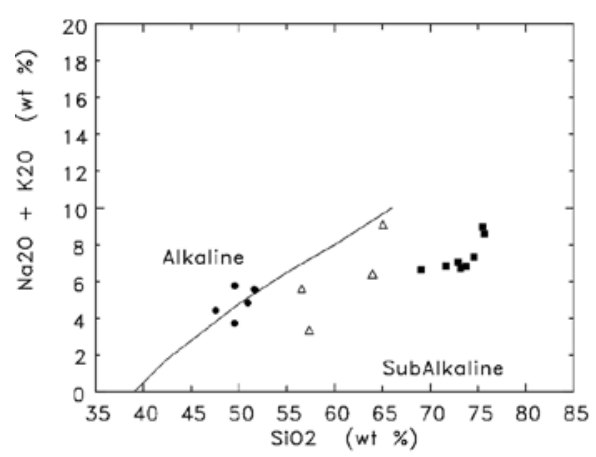

c)

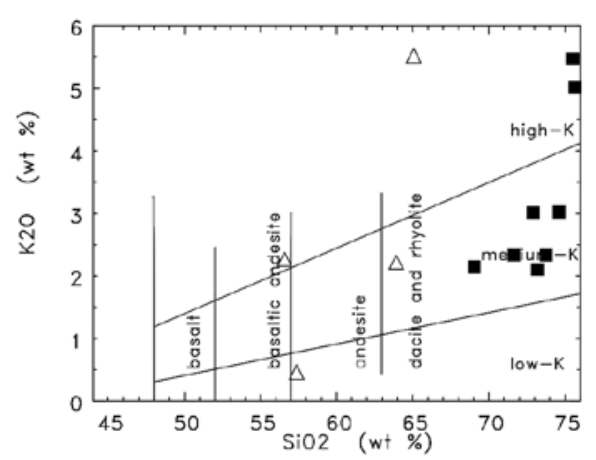

e)

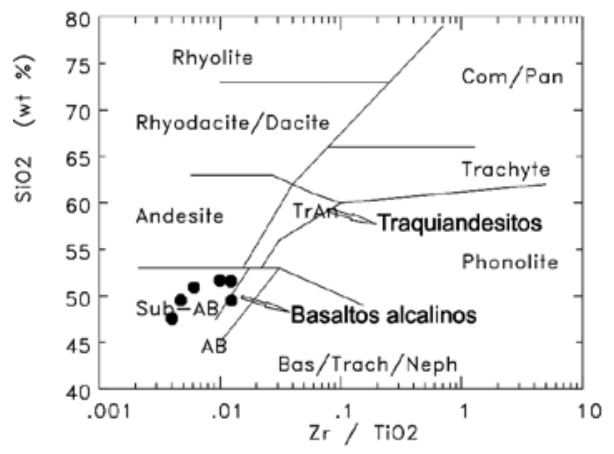

b)

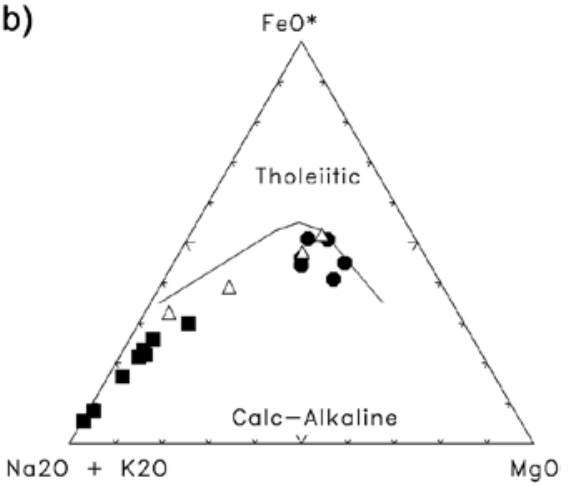

d)

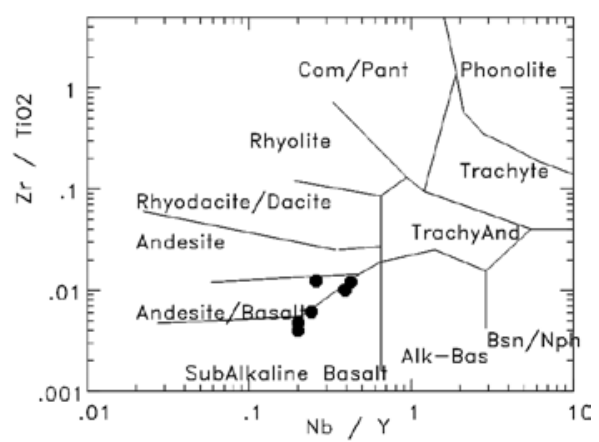

f)

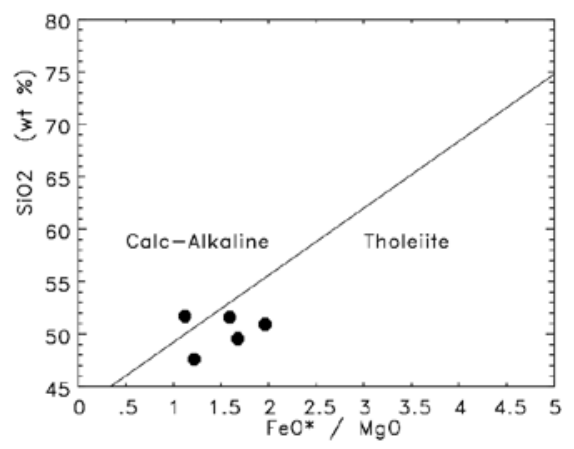

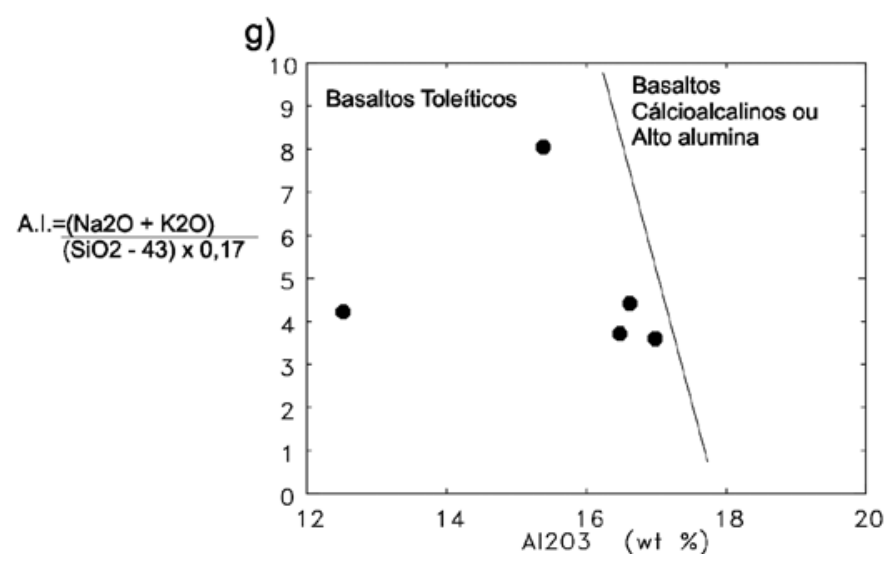

Figura 5 - Diagramas discriminantes de séries magmáticas a) diagrama sílica x total de álcalis de Irvine \& Baragar (1971); b) diagrama AFM de Irvine \& Baragar (1971); c) diagrama classificatório para séries de baixo, médio e alto-K (Le Maitre, 1989); d) e (e) diagramas de Winchester \& Floyd (1977) para classificação de basaltos; f) diagrama $\mathrm{FeO} * \mathrm{MgO} \times \mathrm{SiO}_{2}$ de Miyashiro (1974), para distinção de basaltos calcioalcalinos e toleiticos; ( $g$ ) diagrama A.I (índice alcalico) $x \mathrm{Al}_{2} \mathrm{O}_{3}$ de Middlemost (1975), para distinção de basaltos de baixo alumina (toleitos) e alto alumina (calcioalcalinos). Simbologia: rochas básicas (círculos fechados), rochas intermediárias (triângulos abertos) e rochas ácidas (quadrados fechados). 
ficadas como subalcalinas e apenas uma como alcalina. Dado que as rochas básicas subalcalinas estudadas possuem teores de $\mathrm{FeO}$ e $\mathrm{Al}_{2} \mathrm{O}_{3}$ condizentes com basaltos toleíticos, utilizou-se os diagramas de Miyashiro (1974; Fig. 5f) e Middlemost (1975; Fig. 5g), para a distinção da afinidade química das mesmas. As mesmas séries ora identificadas foram apontadas por diversos autores que estudaram o Complexo Juiz de Fora, como, por exemplo, Oliveira (1982), Grossi Sad \& Barbosa (1985), Heilbron (1993), Dios (1995), Duarte et al. (1997); Duarte (1998); e Heilbron et al. (1998).

Segundo diagrama Le Maitre (1989), os granulitos básicos da série tolética da área de Três Rios são classificados como basaltos (B) e traquiandesitos basál- ticos (S2), enquanto que o granulito básico da série alcalina é classificado como traquibasalto (S1) (Fig. 6a). As rochas da série calcioalcalina de alto-K são quimicamente classificadas como álcali-feldspato granito, quartzo monzonito e quartzo monzodiorito e as rochas da série calcioalcalina de médio-K são granitos e granodioritos (Fig. 6b). Pelo índice de saturação em alumina (IAS) ou índice de Shand, diagrama de Maniar \& Piccoli (1989), os granulitos calcioalcalinos são classificados como metaluminosos a fracamente peraluminosos (índice de Shand igual a 1,0), mostrando que seus protólitos tratam-se de granitóides do tipo I Cordilheirano (Pitcher 1983). Esta característica é corroborada pela presença de hornblenda, mineral pobre em $\mathrm{Al}_{2} \mathrm{O}_{3}$ e estável em rochas a)

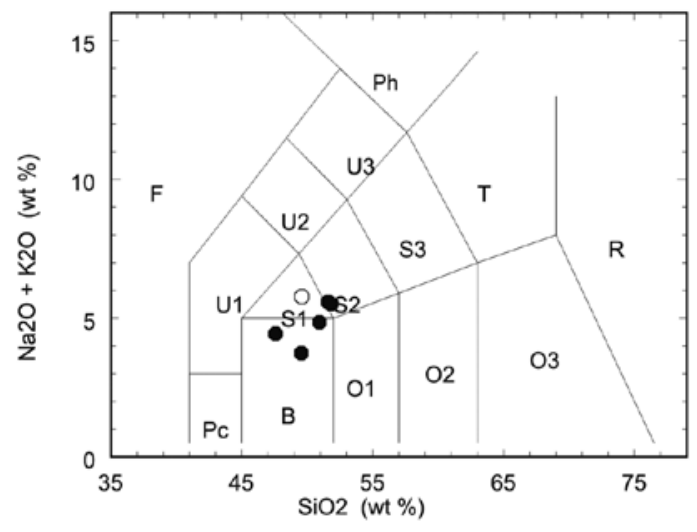

b)

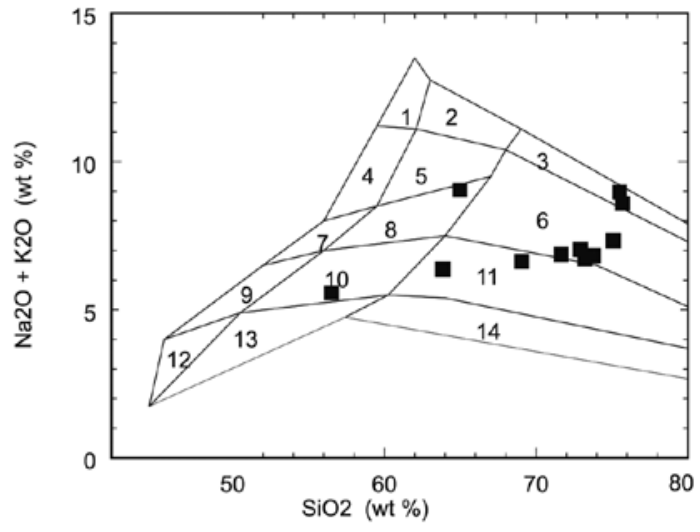

c)

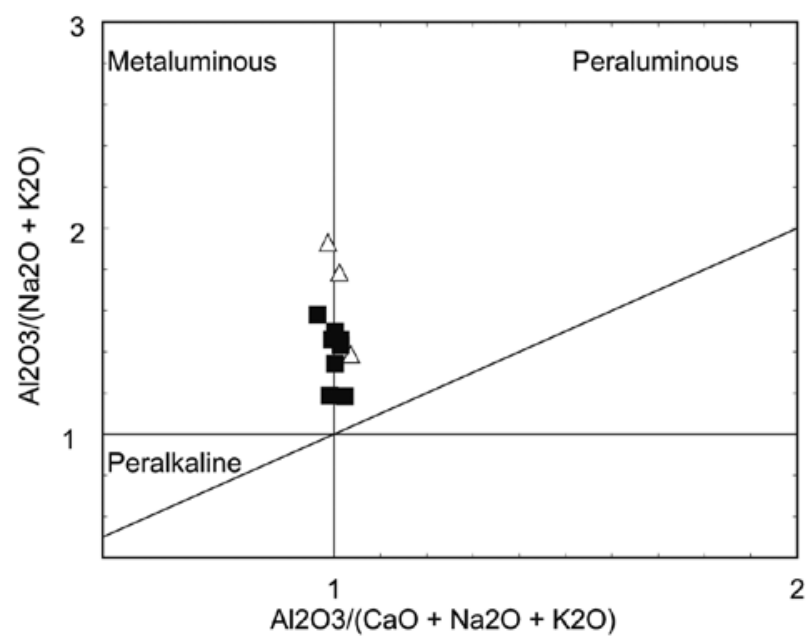

Figura 6 - a) Diagrama de classificação química de Le Maitre (1989); B: Basaltos, S1: Traquibasaltos e S2: Traquiandesitos basálticos; b) Classificação química das rochas da série calcioalcalina (Middlemost, 1985). 1- Álcali-feldspato sienito; 2 - Álcali-feldspato quartzo sienito; 3 - Álcali-feldspato granito; 4 - Sienito; 5 - Quartzo sienito; 6 - Granito; 7 - Monzonito; 8 - Quartzo monzonito; 9 - Monzodiorito; 10 - Quartzo mozondiorito; 11 - Granodiorito; 12 - Diorito e gabro; 13 - Quartzo diorito; 14 - Tonalito.; c) Caráter metaluminoso dos ortogranulitos/ortognaisses calcioalcalinos, (diagrama de Maniar \& Piccoli 1989). Simbologia: rochas básicas toleiticas (círculos fechados); rochas básica alcalina (círculo aberto); rochas intermediárias (triângulos abertos) e rochas ácidas (quadrados fechados). 
com IAS até próximo de 1,1 (Fig. 6c).

Os dados geoquímicos permitiram a subdivisão das rochas do Complexo Juiz de Fora na região de Três Rios em três grupos distintos:

1) um grupo subalcalino, constituído de rochas de composição básica dispostas ao longo de um trend toleítico;

2) outro grupo subalcalino, constituído de rochas intermediárias a ácidas dispostas ao longo de um trend calcioalcalino; $\mathrm{e}$

3) um terceiro grupo, de caráter transicional e afinidade alcalina, que inclui apenas granulitos básicos.

Além de acompanharem trends evolutivos distintos, os dois grupos subalcalinos são separados por um gap de $\approx 56 \%$ a $62 \% \mathrm{SiO}_{2}$. Duarte (1998) e Duarte \& Valente (1999), observando estas características na região de Juiz de Fora ( aap de $\approx 50 \%$ a $55 \% \mathrm{SiO}_{2}$ ), aliadas à realização de análise quantitativa, sugeriram que não há cogeneticidade entre os granulitos básicos $\mathrm{e}$ as rochas calcioalcalinos.

Geoquímica dos Elementos Terras Raras Vários autores consideram que as razões entre elementos incompatíveis não variam substancialmente em processo de cristalização fracionada, sendo esperadas variações de até 1,5 vezes dentre rochas cogenéticas (p. ex., Cox et al. 1979).

Investigações do comportamento dos elementos terras raras (ETR) durante o metamorfismo (Cullers et al. 1974; Muecke et al. 1979) indicam que, embora já se tenha observado mobilidades dos ETR durante eventos metassomáticos, geralmente há pouca modificação dos padrões de ETR durante o evento metamórfico, o que permite utilizá-los no estudo do protólito.

A abordagem petrogenética baseada nos ETR fez-se necessária para a distinção de prováveis grupos cogenéticos que possam existir dentre as amostras estudadas do COMPLEXO JUIZ DE FORA. Para tal, foram normalizados os ETR para o condrito de Boynton (1984) e assim calculada a razão $[\mathrm{La} / \mathrm{Yb}]_{\mathrm{N}}$. A tabela 3 disponibiliza os valores das razões $[\mathrm{La} / \mathrm{Yb}]_{\mathrm{N}}$, os valores das anomalias de $\mathrm{Eu} / \mathrm{Eu}^{*}$ e os teores de $\mathrm{SiO}_{2}$ e $\mathrm{MgO}$ para todas as amostras estudadas. A análise de ETR permitiu distinguir duas possíveis suítes para a série cálcioalcalina de alto- $K$, três para a série cálcioalcalina de médio-K e duas para a série toleítica.

A série cálcioalcalina de alto-K é representada por granulitos intermediários a ácidos, sendo definidas duas possíveis suítes (Figs. 7a e 7b):

i) granulitos intermediários cujos valores da razão $[\mathrm{La} / \mathrm{Yb}]_{\mathrm{N}}$ variam de 8 a 13 e as anomalias de Eu são positivas $(1,211-2,371)$; e

ii) granulitos ácidos cujas razões $[\mathrm{La} / \mathrm{Yb}]_{\mathrm{N}}$ variam de 25 a 36 e as anomalias de Eu são tanto positivas quanto negativas.

A série cálcioalcalina de médio-K é a que possui maior número de amostras (sete no total), sendo composta, em sua maioria, por rochas ácidas. Pode ser subdividida em três possíveis suítes (Figs. 7c, 7d e 7e):

i) grupo representado por granulitos ácidos, cujos valores das razões $[\mathrm{La} / \mathrm{Yb}]_{\mathrm{N}}$ variam de 43 a 54 e as ano-
Tabela 3 - Valores da razão [La/Yb] $]_{N}$ (normalizados para o condrito de Boynton, 1984) das amostras estudadas.

\begin{tabular}{l|c|c|c|c}
\hline \multicolumn{5}{c}{ Série cálcio-alcalina de alto-K } \\
\hline Amostras & $\mathrm{SiO}_{2}$ & $\mathrm{MgO}$ & $\mathrm{La} / \mathrm{Yb}_{\mathrm{N}}$ & $\mathrm{Eu} / \mathrm{Eu}^{*}$ \\
\hline TR-JEF-03B & 75,72 & 0,11 & 25,17 & 0,73 \\
\hline TR-JEF-04A & 74,82 & 0,02 & 35,16 & 2,49 \\
\hline JA-17-JEFC & 63,30 & 0,74 & 12,76 & 1,21 \\
\hline ECII-98-IV-50 & 55,90 & 5,60 & 8,98 & 2,37 \\
\hline
\end{tabular}

Série cálcio-alcalina de médio-K

\begin{tabular}{l|c|c|c|c}
\hline TR-JEF-04C & 74,49 & 0,29 & 43,50 & 1,08 \\
\hline TR-JEF-04B & 73,62 & 0,39 & 48,68 & 0,87 \\
\hline TR-JEF-01-C1 & 73,05 & 0,53 & 92,63 & 1,12 \\
\hline TR-JEF-03C & 71,65 & 0,44 & 54,09 & 1,31 \\
\hline TR-JEF-01A & 70,76 & 0,51 & 84,85 & 0,47 \\
\hline ECII-98-I-10 & 67,61 & 1,18 & 29,41 & 1,01 \\
\hline JA-17-JEFD & 62,32 & 2,02 & 21,25 & 0,79
\end{tabular}

Série toleítica

\begin{tabular}{l|c|c|c|c}
\hline ECII-98-I-15A & 56,34 & 4,76 & 1,88 & 0,99 \\
\hline ECII-97-I-10F & 50,70 & 5,41 & 3,86 & 0,72 \\
\hline ECII-97-III-11 & 50,65 & 8,76 & 5,29 & 0,81 \\
\hline JA-17-JEFB & 50,44 & 5,47 & 4,34 & 0,51 \\
\hline TR-JEF-01 & 49,57 & 5,98 & 1,78 & 1,22 \\
\hline TR-JEF-03A & 46,20 & 8,71 & 1,59 & 1,12 \\
\hline
\end{tabular}

Série Alcalina

\begin{tabular}{l|c|c|c|c}
\hline JA-17-JEFA & 48,97 & 5,73 & 13,12 & 1,02 \\
\hline
\end{tabular}

malias de Eu podem ser tanto negativas como positivas.

ii) granulitos ácidos com razões $[\mathrm{La} / \mathrm{Yb}]_{\mathrm{N}}$ muito elevadas, entre 84 a 93, com anomalias de Eu tanto positivas quanto negativas.

iii) grupo representado por um granulito intermediário e um ácido, cujos valores das razões [La/Yb] ${ }_{N}$ são de 21 e 30. Essas amostras apresentam ligeiras anomalias de $\mathrm{Eu}$, tanto positivas quanto negativas.

As rochas básicas toleíticas são representadas por dois grupos distintos, relacionados possivelmente a fontes distintas. No grupo I, todas as amostras possuem anomalias positivas de Eu e razões $[\mathrm{La} / \mathrm{Yb}]_{\mathrm{N}}$ entre 1 e 2, apontando para ambiente de fundo oceânico do tipo E-MORB. O grupo II é mais fracionado que o grupo I, com razões $[\mathrm{La} / \mathrm{Yb}]_{\mathrm{N}}$ pouco mais elevadas e anomalias negativas de Eu. As razões $[\mathrm{La} / \mathrm{Yb}]_{\mathrm{N}}$ entre 3 e 6, quando comparadas áquelas da literatura (Wilson, 1991), 


\section{a) \\ Grupo I}

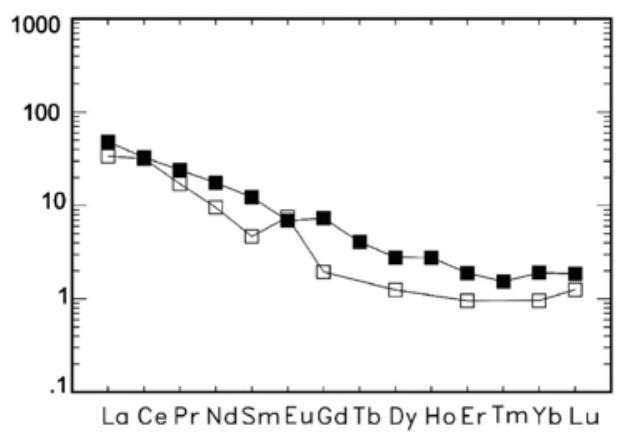

c)

Grupo I

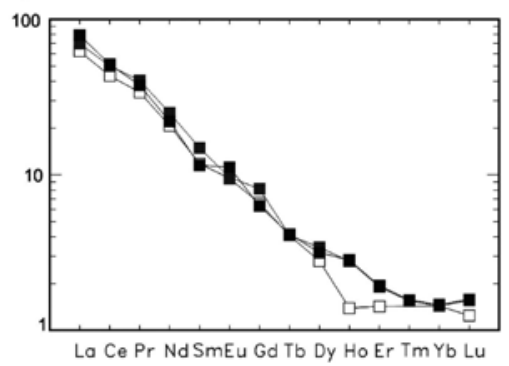

b)

\section{Grupo II}

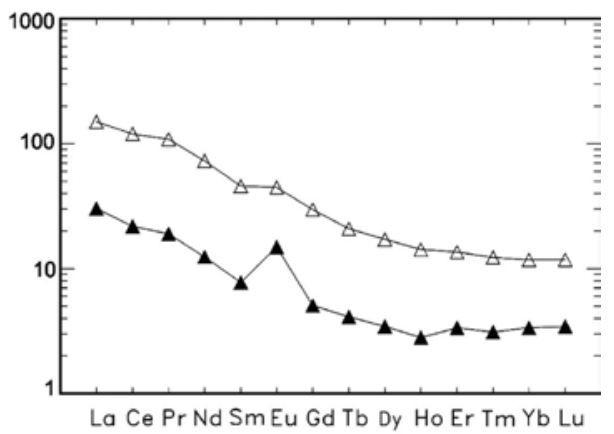

d)

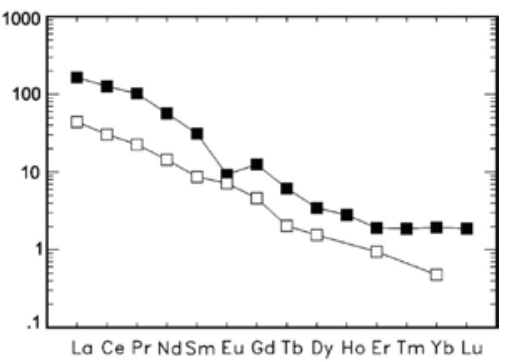

e)

Grupo III

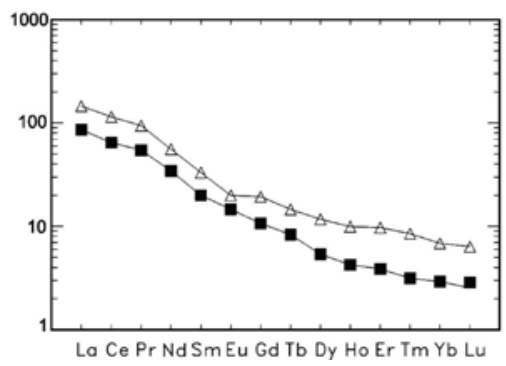

Figura 7 - Padrão de ETR de cada possível suite das séries cálcioalcalinas de alto e médio-K.

indicam magmatismo toleítico intraplaca oceânico ou continental, tipo Kilauea ou Snake River, respectivamente (Figs. 8a e 8b).

O diagrama da amostra da série alcalina é apresentado para que se possa visualizar o padrão de ETR. Verifica-se que esta amostra possui forte depleção de ETRp e enriquecimento em ETR1, com valores [La/Yb] ${ }_{\mathrm{N}}$ de 13,117 o que aponta para um ambiente intraplaca oceânico tipo Kohala (Fig. 8c).

Ambientação Tectônica Diagramas de discriminação de ambientes tectônicos têm sido utilizados com cautela para rochas précambrianas, uma vez que foram elaborados com base em eventos do Fanerozóico. Para estudar o conjunto de ortogranulitos/ortognaisses calcioalcalinos do Complexo Juiz de Fora, foram utilizados os diagramas de Pearce et al. (1984). A análise dos diagramas (Fig. 9a) mostra que as amostras das series calcioalcalinas de médio e alto-K ocupam predominantemente o campo de granitos de arco vulcânico.

A comparação das assinaturas geoquímicas das amostras com padrões de mesma ambientação, normalizados pelo granito de crista oceânica (ORG) de Pearce et al. (1984), nos revela que, com exceção de uma amostra que se assemelha a granitos de arco do Chile, há uma grande semelhança entre os ortogranulitos da série calcialcalina de médio-K do Complexo Juiz de Fora com o granito de arco vulcânico da Jamaica (Fig. 9b).

Para as rochas da série de alto-K, essa comparação foi feita para cada uma das suítes (grupos) aqui definidas. Assim, o grupo I desta série apresenta padrão semelhante àquele de granitos de arco vulcânico do Chile, apesar dos granitos do Chile serem mais enriquecidos nos elementos imóveis (Fig. 9c). Para o grupo 


\section{Série Toleítica}

Grupo I

a)

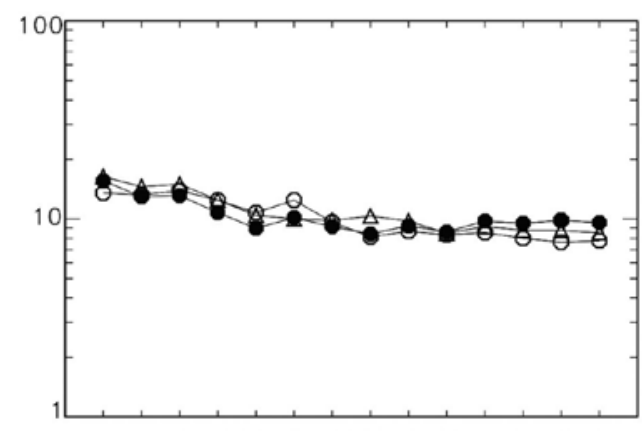

La Ce Pr Nd SmEu Gd Tb Dy Ho Er TmYb Lu
Grupo II

b)

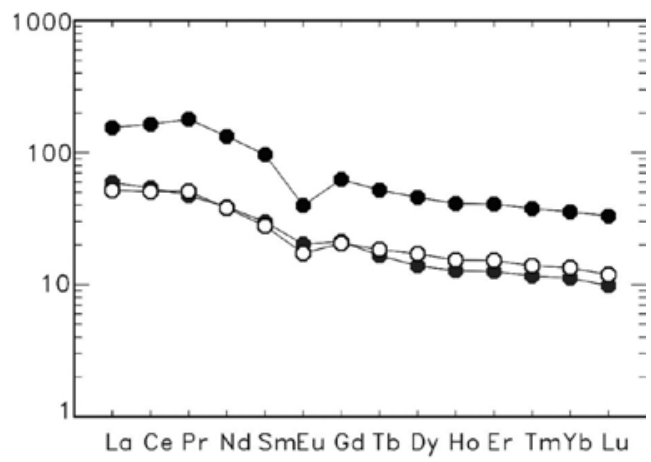

c)

Série Alcalina

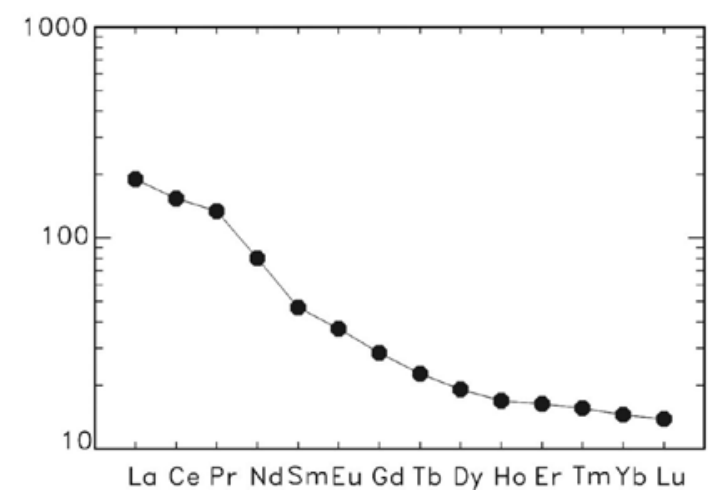

Figura 8 - Padrão de ETR das possiveis suites da série toleítica e da amostra alcalina.

II, uma amostra apresentou padrão semelhante àquele de granitos de arco vulcânico da Jamaica, enquanto a outra possui um padrão semelhante àquele de granitos de arco vulcânico do Chile (Fig. 9d).

As correlações e tendência observadas sugerem que os ortogranulitos/ortognaisses calcioalcalinos do Complexo Juiz de Fora formaram-se em ambiente de arco magmático. Para os regimes tectônicos atuais, esse tipo de magmatismo calcioalcalino está fortemente relacionado a ambientes tectônicos compressivos, desenvolvidos em arcos mais maduros e margens continentais ativas.

Com base na assinatura dos elementos terras raras, as rochas básicas toleiíticas foram formadas em ambientes extensionais tanto do tipo MORB, quanto intraplaca oceânico ou continental, enquanto que o metabasito alcalino tem assinaturas típicas de ambiente intraoceânico.

GEOCRONOLOGIA U-Pb EM ZIRCÃO POR LAICPMS O estudo geocronológico consistiu na análise de dois litotipos encontrados em campo, um ortognaisse ácido (TR-JEF-O1C1), formado pelo retrometamorfismo de um ortogranulito, e um ortogranulito básico (TRJEF-01). Estes litotipos foram caracterizados pelo estudo litogeoquímico como: calcioalcalino de médio-K e toleíto, respectivamente. As relações observadas em campo entre esses dois litotipos sugerem que o ortogranulito básico seja mais antigo que o ortognaisse ácido.

Através desse estudo, espera-se determinar as idades de cristalização dos protólitos e, se possível, de metamorfismo registrado nos grãos de zircão dessas litologias. Além do que, a determinação das idades de cristalização responderá se essas rochas representam parte do embasamento paleoproterozóico do Orógeno Ribeira, visto que a comparação geoquímica aponta para uma possível corre-lação destas litologias com o Complexo Juiz de Fora, como é encontrado em Fernandes André (2009).

Ortognaisse granodiorítico da série cálcioalcalina de médio-K Foi selecionada uma amostra de um ortognaisse granodiorítico (amostra TR-JEF-O1C1) da 
a)

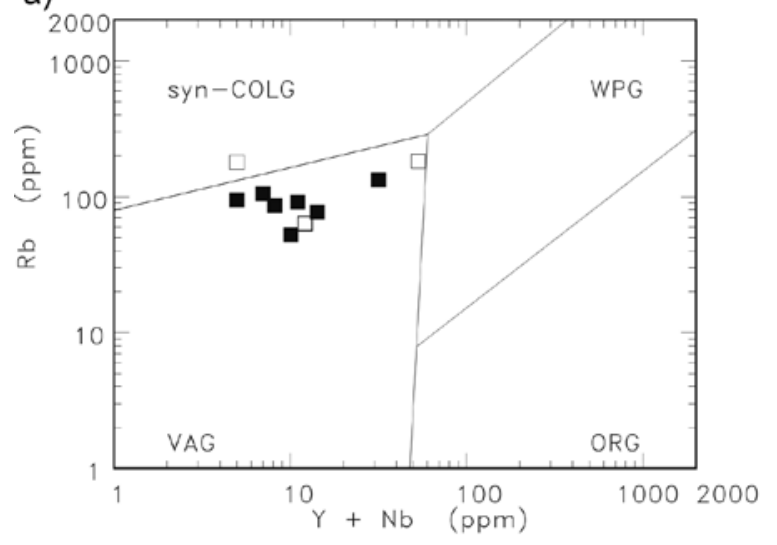

c)

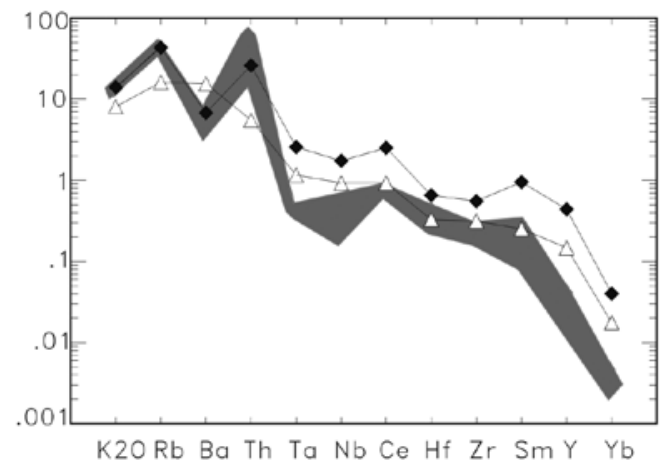

b)

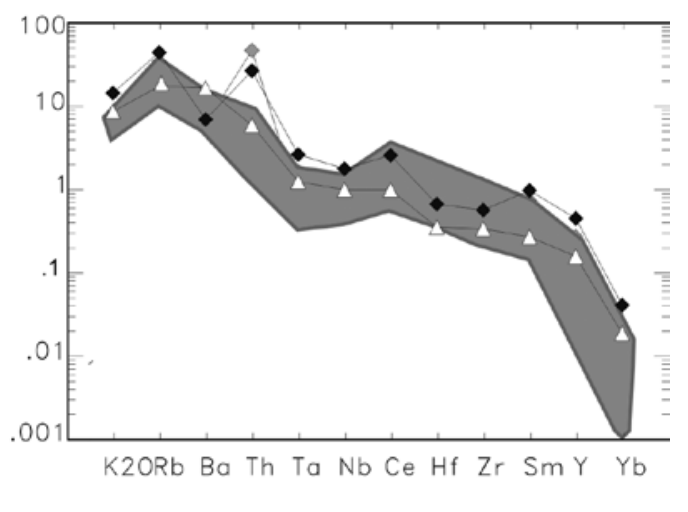

d)

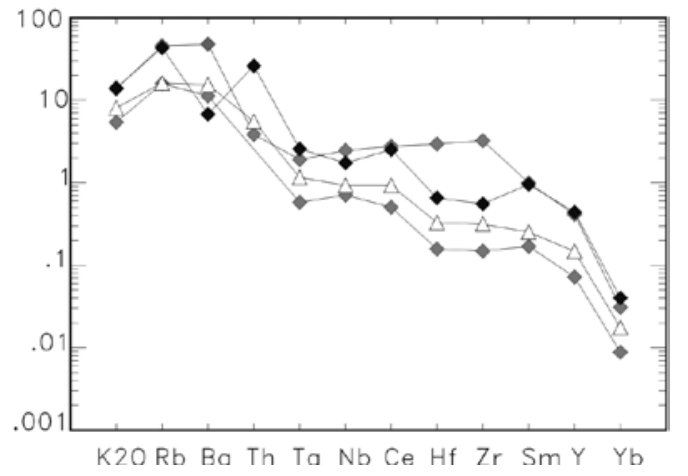

Figura 9 - Ortogranulitos das séries calcioalcalinas plotados no diagrama $\mathrm{Rb} \times Y+\mathrm{Nb}(\mathrm{a})$, e nos aranhogramas normalizados por Ocean Ridge Granite $(O R G)$ (b), (c) e (d) de Pearce et al. (1984). Legenda: granito de arco vulcânico do Chile (losango fechado); granito de arco vulcânico da Jamaica (triângulo aberto); amostras das séries de médio e alto-K deste trabalho (campo preenchido); amostras da série de alto-K do grupo II (losango cinza).

série cálcioalcalina de médio-K aflorante no $\mathrm{km} 19$ da BR-040 (rodovia que liga o Rio de Janeiro a Belo Horizonte), nas proximidades da cidade de Três Rios (Fig. 2). Foram selecionados e montados 41 grãos de zircão, dentre os quais, 6 são pontas de prismas, selecionadas com intuito de averiguar eventos metamórficos. No total, foram analisados 15 grãos, sendo que em 4 as análises foram realizadas no centro e na borda dos cristais.

Todos os grãos são da fração diamagnética. Os grãos não são de boa qualidade, pois apresentam algumas fraturas e até mesmo algumas inclusões, o que poderia resultar numa má qualidade dos resultados. Entretanto, a alta resolução espacial do feixe de laser (a $40 \mu \mathrm{m}$ de diâmetro) possibilita uma análise precisa dos setores mais preservados do grão. $\mathrm{O}$ hábito desses grãos pode ser bipiramidal, lenticular, equidimensional e subédrico, com tamanho variando de 100 a $200 \mu \mathrm{m}$.

RESULTADOS OBTIDOS $\mathrm{Na}$ análise foram utilizadas todas as famílias de zircão, incluindo as pontas de prismas e centro de alguns grãos. Os grãos analisados apresentam perda de chumbo e são todos discordantes. $\mathrm{O}$ fato das elipses estarem agrupadas impossibilitou o cálculo da discórdia (Tab. 4 e Fig. 10). A análise dos resultados obtidos revela que as idades encontradas são paleoproterozóicas, mesmo para aqueles grãos em que o spot foi posicionado na borda. Em nenhum dos grãos analisados, mesmo em pontas de prismas e bordas de grãos, foram obtidas idades de eventos posteriores. Heilbron et al. (2001) obtiveram idades paleoproterozóicas no intervalo de 2,14 a 2,07 Ga para o conjunto calcioalcalino do Complexo Juiz de Fora na região homônima.

Ortogranulito básico da série toleítica Foi selecionada uma amostra de um ortogranulito básico (amostra TR-JEF-01) do tipo E-MORB da série toleítica aflorante na mesma localidade daquela da amostra anterior (Fig. 2). Foram selecionados 23 grãos de zircão, dentre os quais, 13 são diamagnéticos e 10 são paramagnéticos. No entanto, no processo de polimento, alguns cristais foram perdidos, restando apenas 16 que foram analisados, nos centros e/ou nas bordas.

A escolha de grãos do Frantz final paramagnético foi necessária porque eram poucos os grãos de zircão na fração diamagnética, que se mostrou repleta de apatita. Os zircões diamagnéticos são pardos e incolo- 
Tabela 4 - Resultados obtidos da análise U-Pb (LA-ICPMS) em zircão do ortogranulito félsico do Complexo Juiz de Fora da região de Três Rios (RJ).

\begin{tabular}{|c|c|c|c|c|c|c|c|c|c|c|c|c|c|}
\hline Grão & ${ }^{207} \mathrm{~Pb} /{ }^{206} \mathrm{~Pb}$ & $\begin{array}{c}2 \sigma \text { erro } \\
(\%)\end{array}$ & ${ }^{207} \mathrm{~Pb} /{ }^{235} \mathrm{U}$ & $\begin{array}{c}2 \sigma \text { erro } \\
(\%)\end{array}$ & ${ }^{206} \mathrm{~Pb} /{ }^{238} \mathrm{U}$ & $\begin{array}{c}2 \sigma \text { erro } \\
(\%)\end{array}$ & rho & $\begin{array}{l}{ }^{207} \mathrm{~Pb} /{ }^{206} \mathrm{~Pb} \\
\text { idade (Ma) }\end{array}$ & $2 \sigma$ erro & $\mid \begin{array}{c}{ }^{207} \mathrm{~Pb} /{ }^{235} \mathrm{U} \\
\text { Idade } \\
(\mathrm{Ma})\end{array}$ & $2 \sigma$ erro & $\begin{array}{c}{ }^{206} \mathrm{~Pb} /{ }^{238} \mathrm{U} \\
\text { idade } \\
(\mathrm{Ma})\end{array}$ & $2 \sigma$ erro \\
\hline $\begin{array}{l}\mathrm{Z1} \text {, } \\
\text { centro }\end{array}$ & 0,1281 & 2,8 & 5,3744 & 6,1 & 0,3043 & 5,5 & 0,89 & 2072,1 & $\pm 48,5$ & 1880,8 & $\pm 52,5$ & 1712,4 & $\pm 106,7$ \\
\hline $\begin{array}{l}\mathrm{Z} 1, \\
\text { borda }\end{array}$ & 0,1281 & 1,3 & 5,0346 & 2,8 & 0,2849 & 2,5 & 0,89 & 2072,7 & $\pm 22,7$ & 1825,2 & $\pm 23,9$ & 1616,2 & $\pm 45,9$ \\
\hline $\begin{array}{l}\mathrm{Z} 2, \\
\text { centro }\end{array}$ & 0,1304 & 1,1 & 5,2267 & 2,3 & 0,2907 & 2,0 & 0,88 & 2103,1 & $\pm 18,7$ & 1857,0 & $\pm 19,3$ & 1645,2 & $\pm 37,4$ \\
\hline $\begin{array}{l}\mathrm{Z} 2, \\
\text { borda }\end{array}$ & 0,1378 & 1,9 & 5,4733 & 4,3 & 0,2880 & 3,8 & 0,89 & 2199,9 & $\pm 33,7$ & 1896,4 & $\pm 36,5$ & 1631,7 & $\pm 70,0$ \\
\hline $\mathrm{Z3}$ & 0,1295 & 1,6 & 5,4883 & 3,4 & 0,3074 & 3,0 & 0,88 & 2090,9 & $\pm 27,3$ & 1898,8 & $\pm 28,9$ & 1728,0 & $\pm 58,9$ \\
\hline $\mathrm{Z4}$ & 0,1247 & 0,8 & 4,7708 & 1,7 & 0,2776 & 1,5 & 0,87 & 2023,9 & $\pm 14,9$ & 1779,8 & $\pm 14,5$ & 1579,1 & $\pm 26,9$ \\
\hline $\mathrm{Z} 5$ & 0,1330 & 1,0 & 5,5927 & 2,2 & 0,3050 & 1,9 & 0,88 & 2138,0 & $\pm 17,9$ & 1915,0 & $\pm 18,6$ & 1715,9 & $\pm 37,3$ \\
\hline Z6 & 0,1351 & 1,5 & 5,8687 & 3,2 & 0,3151 & 2,9 & 0,89 & 2165,0 & $\pm 26,1$ & 1956,6 & $\pm 28,1$ & 1765,8 & $\pm 58,1$ \\
\hline $\mathrm{Z7}$ & 0,1222 & 1,0 & 5,2400 & 1,9 & 0,3110 & 1,6 & 0,86 & 1988,3 & $\pm 17,0$ & 1859,1 & $\pm 16,1$ & 1745,8 & $\pm 32,5$ \\
\hline $\begin{array}{l}\mathrm{Z} 8, \\
\text { borda }\end{array}$ & 0,1247 & 1,1 & 5,0993 & 2,3 & 0,2966 & 2,0 & 0,88 & 2024,5 & $\pm 19,7$ & 1836,0 & $\pm 19,6$ & 1674,4 & $\pm 38,6$ \\
\hline $\begin{array}{l}\mathrm{Z8}, \\
\text { centro }\end{array}$ & 0,1238 & 0,9 & 5,1569 & 1,8 & 0,3021 & 1,6 & 0,86 & 2012,0 & $\pm 16,3$ & 1845,5 & $\pm 15,5$ & 1701,5 & $\pm 30,6$ \\
\hline Z9 & 0,1264 & 1,7 & 5,2750 & 3,6 & 0,3026 & 3,2 & 0,89 & 2049,1 & $\pm 29,8$ & 1864,8 & $\pm 31,0$ & 1704,0 & $\pm 62,4$ \\
\hline $\begin{array}{l}\text { Z10, } \\
\text { núcleo }\end{array}$ & 0,1256 & 1,1 & 5,8091 & 2,2 & 0,3355 & 1,9 & 0,87 & 2037,1 & $\pm 18,7$ & 1947,8 & $\pm 18,8$ & 1864,8 & $\pm 40,8$ \\
\hline $\begin{array}{l}\mathrm{Z10}, \\
\text { borda }\end{array}$ & 0,1237 & 0,9 & 5,1494 & 1,9 & 0,3019 & 1,6 & 0,87 & 2010,3 & $\pm 16,5$ & 1844,3 & $\pm 15,9$ & 1700,8 & $\pm 31,4$ \\
\hline Z11 & 0,1280 & 1,1 & 5,2324 & 2,3 & 0,2965 & 2,0 & 0,88 & 2070,3 & $\pm 19,3$ & 1857,9 & $\pm 19,4$ & 1674,1 & $\pm 37,9$ \\
\hline $\mathrm{Z} 12$ & 0,1239 & 1,4 & 5,1063 & 3,0 & 0,2989 & 2,6 & 0,88 & 2013,1 & $\pm 25,0$ & 1837,2 & $\pm 25,4$ & 1685,9 & $\pm 50,6$ \\
\hline Z13 & 0,1184 & 1,9 & 4,1813 & 4,0 & 0,2562 & 3,6 & 0,89 & 1931,9 & $\pm 33,3$ & 1670,4 & $\pm 33,0$ & 1470,2 & $\pm 58,8$ \\
\hline Z14 & 0,1259 & 1,2 & 4,9636 & 2,5 & 0,2860 & 2,2 & 0,88 & 2041,1 & $\pm 20,4$ & 1813,1 & $\pm 20,8$ & 1621,5 & $\pm 39,8$ \\
\hline Z15 & 0,1371 & 1,3 & 4,7872 & 2,7 & 0,2532 & 2,4 & 0,89 & 2191,1 & $\pm 21,7$ & 1782,6 & $\pm 22,7$ & 1455,0 & $\pm 39,1$ \\
\hline
\end{tabular}

res, lenticulares a bipiramidais e com raras fraturas; os paramagnéticos são equidimensionais, fraturados e por vezes apresentam inclusões de minerais opacos. Seus tamanhos variam entre 100 e $300 \mu \mathrm{m}$.

RESULTADOS OBTIDOS Dos 16 grãos de zircão analisados, foram obtidos resultados em 20 spots (Tab. 5). Como não foi possível calcular uma discórdia, utilizou-se a média (Weighted Average) das ida- des ${ }^{206} \mathrm{~Pb} /{ }^{238} \mathrm{U}$. Utilizando-se para tal os 20 spots, esta média apresenta um valor de MSWD=5,4 (Fig. 11a). O elevado valor do MSWD obtido indica um baixo grau de probabilidade deste grupo de idades compor uma única população. Sendo assim, optou-se por uma análise mais detalhada, a partir da qual o conjunto foi separado em dois agrupamentos distintos, obtendo-se então duas idades médias ${ }^{206} \mathrm{~Pb} /{ }^{238} \mathrm{U}$ : a) $615,9 \pm 6,4$ Ma (MSWD = 1,2, englobando 7 spots; Fig. 11b); e, 


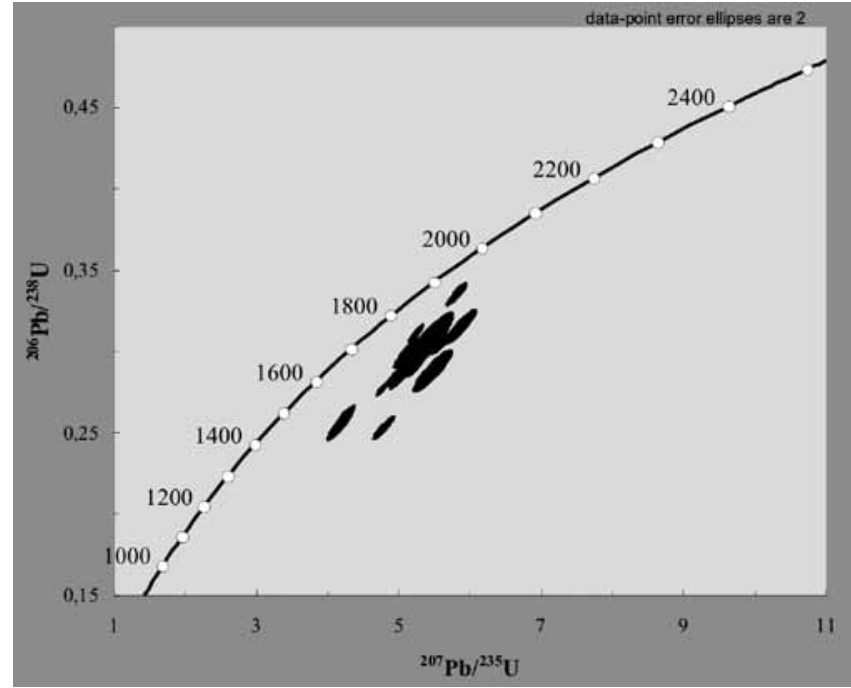

Figura 10 - Diagrama concórdia mostrando as elipses agrupadas dos grãos analisados do ortognaisse ácido da na região de Três Rios (RJ). b) $589,1 \pm 5 \mathrm{Ma}$ (MSWD = 1,4, englobando 13 spots; Fig. 11c). Vale ressaltar que não existe relação entre os dois agrupamentos de idades e o fato dos grãos serem para ou diamagnéticos ou os spots serem direcionados a núcleo ou borda dos grãos.

GEOQUÍMICA ISOTÓPICA DE Nd E Sr Análises isotópicas de $\mathrm{Nd}$ foram efetuadas para três amostras (TR-JEF-01C1, TR-JEF-01A e TR-JEF-01) de um mesmo afloramento localizado no km 19 da BR-040. A primeira corresponde à rocha ácida da série calcioalcalina de médio-K, enquanto que a última, a um ortogranulito básico da série toleítica. Para a amostra básica obtevese também análise de Sr. As análises foram realizadas no Laboratório de Geocronologia e Isótopos Radiogênicos (LAGIR) da Faculdade de Geologia da UERJ, segundo procedimentos anteriormente descritos.

Idade modelo de $\mathrm{Nd}\left(\mathrm{T}_{\mathrm{DM}}\right)$

Para o conjunto calcioalcalino de médio-K, obteve-se

Tabela 5 - Resultados obtidos da análise U-Pb (LA-ICPMS) em zircão do ortogranulito básico da região de Três Rios. *Agrupamento de cristais de zircão com idade de 589,1 \pm Ma.

\begin{tabular}{|c|c|c|c|c|c|c|c|c|c|c|c|c|c|}
\hline Grão & ${ }^{207} \mathrm{~Pb} /{ }^{206} \mathrm{~Pb}$ & $\begin{array}{l}\sigma \sigma \\
\text { erro } \\
(\%) \\
\end{array}$ & ${ }^{207} \mathrm{~Pb} /{ }^{235} \mathrm{U}$ & $\begin{array}{l}\sigma \sigma \\
\text { erro } \\
(\%) \\
\end{array}$ & ${ }^{206} \mathrm{~Pb} /{ }^{238} \mathrm{U}$ & $\begin{array}{l}\sigma \sigma \\
\text { erro } \\
(\%)\end{array}$ & rho & $\begin{array}{l}{ }^{207} \mathrm{~Pb} / 206 \mathrm{~Pb} \\
\text { idade }(\mathrm{Ma})\end{array}$ & $\begin{array}{c}2 \sigma \\
\text { erro }\end{array}$ & $\begin{array}{l}{ }^{207} \mathrm{~Pb} /{ }^{235} \mathrm{U} \\
\text { Idade (Ma) }\end{array}$ & $\begin{array}{c}2 \sigma \\
\text { erro }\end{array}$ & $\begin{array}{l}{ }^{206} \mathrm{~Pb} /{ }^{238} \mathrm{U} \\
\text { idade (Ma) }\end{array}$ & $\begin{array}{l}2 \sigma \\
\text { erro }\end{array}$ \\
\hline $\mathrm{Z1}$, borda* & 0,0590 & 1,0 & 0,7706 & 1,9 & 0,0948 & 1,6 & 0,86 & 566,0 & $\pm 20,9$ & 580,1 & $\pm 8,4$ & 583,7 & $\pm 10,0$ \\
\hline $\mathrm{Z} 1$, centro* & 0,0601 & 1,0 & 0,7752 & 2,1 & 0,0935 & 1,9 & 0,88 & 609,0 & $\pm 22,3$ & 582,8 & $\pm 9,5$ & 576,0 & $\pm 11,2$ \\
\hline $\mathrm{Z} 2 *$ & 0,060 & 0,9 & 0,7842 & 1,8 & 0,0947 & 1,6 & 0,87 & 605,3 & $\pm 19,3$ & 587,9 & $\pm 8,1$ & 583,4 & $\pm 9,7$ \\
\hline $\mathrm{Z} 3 *$ & 0,0599 & 1,4 & 0,7975 & 3,0 & 0,0965 & 2,7 & 0,89 & 600,8 & $\pm 30,3$ & 595,4 & $\pm 13,6$ & 594,0 & $\pm 16,7$ \\
\hline $\mathrm{Z} 4$, borda* & 0,0583 & 1,1 & 0,7746 & 4,7 & 0,0963 & 4,5 & 0,97 & 542,7 & $\pm 24,2$ & 582,4 & $\pm 20,7$ & 592,6 & $\pm 28,0$ \\
\hline Z4, centro* & 0,0585 & 1,0 & 0,7722 & 3,9 & 0,0957 & 3,8 & 0,97 & 548,8 & $\pm 21,0$ & 581,0 & $\pm 17,2$ & 589,3 & $\pm 23,3$ \\
\hline $\mathrm{Z}^{*}$ & 0,0589 & 0,9 & 0,7935 & 3,2 & 0,0977 & 3,1 & 0,96 & 563,6 & $\pm 18,6$ & 593,2 & $\pm 14,3$ & 600,9 & $\pm 19,3$ \\
\hline Z6* & 0,0594 & 1,9 & 0,7820 & 4,5 & 0,0955 & 4,0 & 0,90 & 580,6 & $\pm 42,1$ & 586,6 & $\pm 20,0$ & 588,1 & $\pm 24,9$ \\
\hline $\mathrm{Z7}$ & 0,0583 & 0,8 & 0,8053 & 1,9 & 0,1002 & 1,7 & 0,91 & 540,8 & $\pm 17,4$ & 599,8 & $\pm 8,6$ & 615,5 & $\pm 11,1$ \\
\hline $\mathrm{Z8}$, centro & 0,0583 & 0,8 & 0,7940 & 1,9 & 0,0987 & 1,7 & 0,90 & 541,6 & $\pm 17,4$ & 593,4 & $\pm 8,4$ & 607,1 & $\pm 10,7$ \\
\hline $\mathrm{Z8}$, borda & 0,0590 & 1,0 & 0,8130 & 2,2 & 0,0999 & 2,0 & 0,90 & 568,5 & $\pm 21,3$ & 604,2 & $\pm 10,2$ & 613,7 & $\pm 13,0$ \\
\hline Z9* & 0,0589 & 1,0 & 0,7894 & 2,3 & 0,0972 & 2,1 & 0,90 & 562,5 & $\pm 22,1$ & 590,8 & $\pm 10,3$ & 598,2 & $\pm 13,0$ \\
\hline Z10, núcleo* & 0,0582 & 1,2 & 0,7796 & 3,4 & 0,0972 & 3,1 & 0,93 & 535,4 & $\pm 27,1$ & 585,3 & $\pm 14,9$ & 598,2 & $\pm 19,5$ \\
\hline Z10, borda* & 0,0591 & 1,2 & 0,7781 & 3,8 & 0,0954 & 3,6 & 0,95 & 571,6 & $\pm 26,7$ & 584,4 & $\pm 16,7$ & 587,7 & $\pm 21,8$ \\
\hline Z11 & 0,0608 & 1,2 & 0,8340 & 4,2 & 0,0994 & 4,1 & 0,96 & 633,2 & $\pm 25,9$ & 615,8 & $\pm 19,5$ & 611,1 & $\pm 25,9$ \\
\hline Z12 & 0,0591 & 2,2 & 0,8197 & 6,3 & 0,1005 & 5,9 & 0,94 & 572,0 & $\pm 47,4$ & 607,9 & $\pm 28,9$ & 617,5 & $\pm 38,3$ \\
\hline Z13 & 0,0585 & 0,8 & 0,8213 & 1,7 & 0,1019 & 1,5 & 0,87 & 548,0 & $\pm 18,4$ & 608,8 & $\pm 7,9$ & 625,3 & $\pm 9,8$ \\
\hline Z14 & 0,0592 & 1,1 & 0,8187 & 2,4 & 0,1003 & 2,1 & 0,88 & 573,9 & $\pm 24,6$ & 607,3 & $\pm 10,9$ & 616,3 & $\pm 13,6$ \\
\hline Z15* & 0,0587 & 1,0 & 0,7869 & 1,9 & 0,0971 & 1,7 & 0,87 & 557,7 & $\pm 20,9$ & 589,4 & $\pm 8,7$ & 597,7 & $\pm 10,6$ \\
\hline Z16* & 0,0599 & 1,8 & 0,7974 & 3,8 & 0,0966 & 3,4 & 0,89 & 599,4 & $\pm 38,1$ & 595,3 & $\pm 17,1$ & 594,3 & $\pm 21,0$ \\
\hline
\end{tabular}


a)

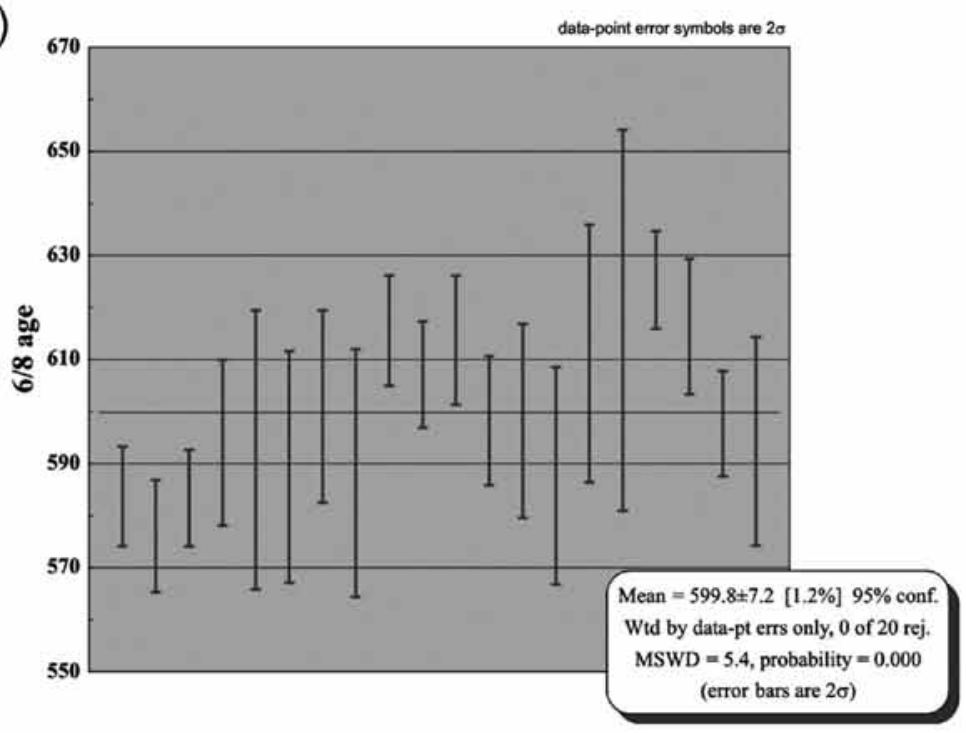

b)

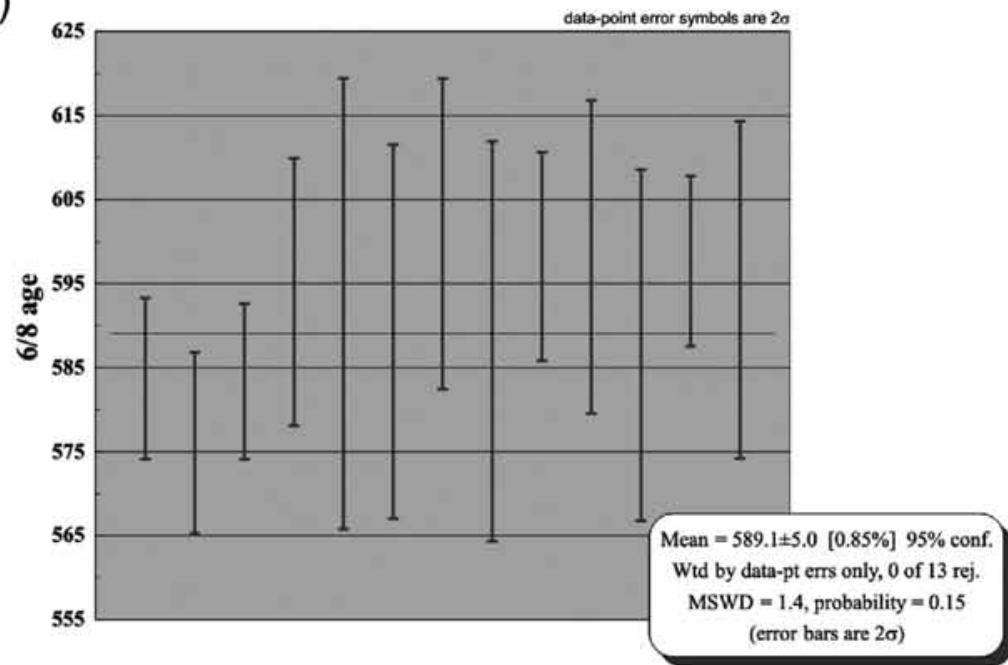

c)

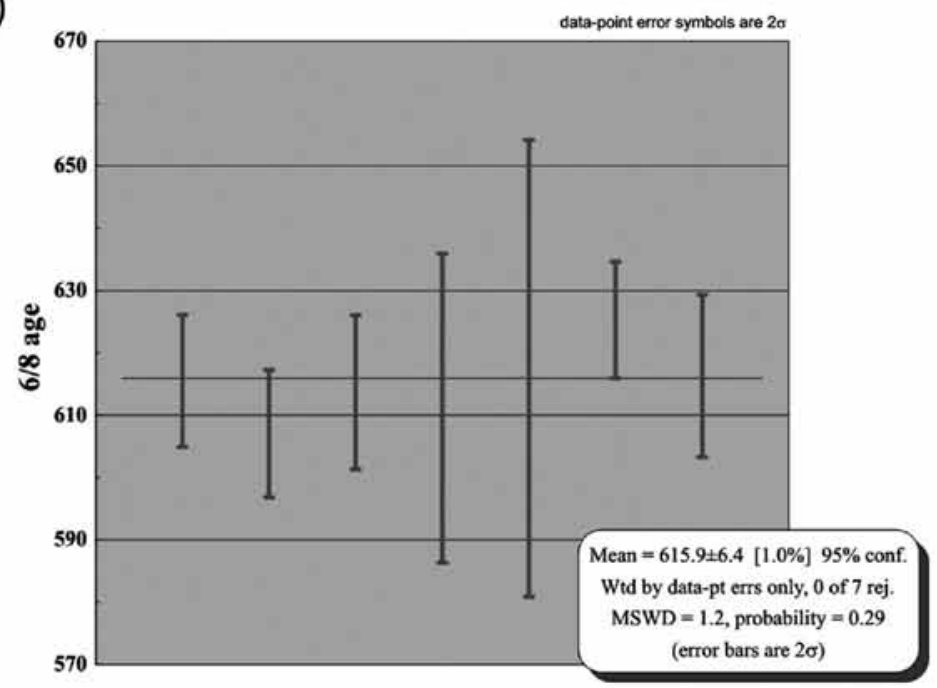

Figura 11 - a) Diagrama das médias das idades ${ }^{206} \mathrm{~Pb} /{ }^{238} \mathrm{U}$ (average ${ }^{206} \mathrm{~Pb}^{238} \mathrm{U}$ age) de 20 spots analisados em zircões do litotipo básico; b) Diagrama das médias das idades ${ }^{206} \mathrm{~Pb} /{ }^{238} \mathrm{U}$ (average ${ }^{206} \mathrm{~Pb} /{ }^{238} \mathrm{U}$ age) de 13 spots analisados em zircões do litotipo básico; c) Diagrama das médias das idades ${ }^{206} \mathrm{~Pb} /{ }^{238} \mathrm{U}$ (average ${ }^{206} \mathrm{~Pb} /{ }^{238} \mathrm{U}$ age) de 7 spots analisados em zircões litotipo básico. 
idade modelo de $\mathrm{Nd}$ de 2,37 Ga (Tab. 6). Os valores de $\varepsilon_{\mathrm{Nd}}^{\mathrm{t}}=-0,63$ e $-0,71$, fracamente negativos, foram calculados utilizando a idade de cristalização de 2,1 Ga obtida para os protólitos (U-Pb, LA-ICPMS em zircão, Machado et al., 1996a) e ajustando os valores isotópicos para o reservatório de manto condrítico, segundo a planilha de cálculo de DePaolo (1981). A integração dos dados revela que os protólitos do conjunto calcioalcalino de médio-K do Complexo Juiz de Fora da área investigada foram gerados num arco magmático juvenil durante o Paleoproterozóico. $\mathrm{O}$ valor obtido foi superior ao anteriomente publicado por Fischel et al. (1998). Estes autores obtiveram, para o Complexo Juiz de Fora da região de Rio Casca e Abre Campo (MG), idades modelo de Nd paleoproterozóicas de 2,22-2,13 Ga, sugerindo também magmatismo juvenil no Paleoproterozóico.

Para o conjunto toleítico não foi possível calcular a idade modelo $\mathrm{T}_{\mathrm{DM}}$ dado o alto valor da razão ${ }^{147} \mathrm{Sm} /{ }^{144} \mathrm{Nd}$ $(0,17294)$ obtido na amostra selecionada. O único dado geocronológico (U-Pb em zircão) disponível na literatura para dos ortogranulitos básicos toleiíticos do Complexo Juiz de Fora indica cristalização dos protólitos em 2,4 $\mathrm{Ga}$ (Heilbron et al. 2001). O valor de $\varepsilon_{\mathrm{Nd}(\mathrm{t}=2,4 \mathrm{Ga})}=+7,70$ indica que o magma básico precursor foi gerado a partir do manto empobrecido (Tab. 6). No entanto, segundo o modelo de De Paolo (1981), este valor é superior àquele esperado para o manto empobrecido no Paleoproterozóico, o que pode indicar idade mais jovem para os protólitos ou fracionamento no sistema Sm-Nd durante o evento metamórfico de alto grau.

Determinação da fonte do magma precursor do conjunto toleítico a partir dos dados isotópicos de $\mathrm{Nd}$ e $\mathrm{Sr}$ As razões ${ }^{143} \mathrm{Nd} /{ }^{144} \mathrm{Nd} \mathrm{e}{ }^{87} \mathrm{Sr} /{ }^{86} \mathrm{Sr}$ permitem a inferência de importantes considerações sobre a fonte mantélica de rochas básicas, pois tais razões isotópicas não são modificadas durante o processo de cristalização fracionada (equilíbrio cristal-líquido) (Rollinson 1993, Wilson 1991).

Para a determinação da fonte do magma precursor do conjunto toleítico, foi necessário regredir as razões isotópicas de $\mathrm{Nd}$ e $\mathrm{Sr}$ para a idade de 2,4 Ga (Heilbron et al. 2001), visando a obtenção das razões iniciais (Tab. 7). Este procedimento é utilizado pelos autores que investigam terrenos de idade semelhante (ex: Kullerud et al. 2006).

Os valores das razões iniciais de $\mathrm{Sr}$ e $\mathrm{Nd}$, lançados no diagrama de ${ }^{143} \mathrm{Nd} /{ }^{144} \mathrm{Nd} \mathrm{x}{ }^{87} \mathrm{Sr} /{ }^{86} \mathrm{Sr}$ para as fontes mantélicas de Zindler e Hart (1986), mostram que o litotipo investigado plota no quadrante dos reservatórios empobrecidos (Fig. 12). Os valores de $\varepsilon_{\mathrm{Nd}}$ e $\varepsilon_{\mathrm{Sr}}(\mathrm{t}=2,4 \mathrm{Ga})$ são, respectivamente, de $+7,7 \mathrm{e}-1,6$. Estes parâmetros indicam que o magma precursor do conjunto toleítico é derivado de uma fonte empobrecida. No entanto, a investigação litogeoquímica aponta para fonte do tipo E-MORB (La/Yb $\left.\mathrm{b}_{\mathrm{N}}>1\right)$.

Exemplos de contribuição de uma fonte mais enriquecida numa fonte de manto empobrecida, na geração de basaltos, são facilmente encontrados na literatura (Zindler \& Hart 1986). Processos de mistura de fonte (P-MORB e N-MORB) são apontados com freqüência na petrogênese de basaltos de fundo oceânico como mostra o gráfico La/Sm $\mathrm{Sm}_{\mathrm{N}}$ versus $\mathrm{Zr} / \mathrm{Nb}$ de Wilson (1991). A projeção das amostras toleíticas do grupo I estabelecido no estudo litogeoquímico no gráfico La/ $\mathrm{Sm}_{\mathrm{N}}$ versus $\mathrm{Zr} / \mathrm{Nb}$ (Fig. 13) sugere mistura de fontes empobrecida e enriquecida na geração destas rochas.

Como a assinatura isotópica sugere geração dos

Tabela 6 - Idade modelo de $N d\left(T_{D M}\right)$ e de $\varepsilon_{N d}^{t}$ para as rochas da região de Três Rios $(R J)$ segundo planilha de cálculo de DePaolo 1981. TR-JEF-01A e TR-JEF-01C1 (ortognaisses da série calcioalcalina de médio-K) e TR-JEF-01 (ortogranulito de composição básica da série toleítica).

\begin{tabular}{l|c|c|c|c|c|c|c}
\hline Amostra & $\mathrm{Sm}(\mathrm{ppm})$ & $\mathrm{Nd}(\mathrm{ppm})$ & ${ }^{147} \mathrm{Sm} /{ }^{144} \mathrm{Nd}$ & ${ }^{143} \mathrm{Nd} /{ }^{144} \mathrm{Nd}$ & $\varepsilon_{(0)}$ & $\varepsilon_{\mathrm{Nd}(\mathrm{t})}$ & $\mathrm{T}_{\mathrm{DM}}(\mathrm{Ma})$ \\
\hline TR-JEF-01A & 6,3 & 39,38 & 0,09676 & $0,5112 \pm 7$ & $-27,66$ & $-0,71(\mathrm{t}=2,1 \mathrm{Ga})$ & 2371 \\
\hline TR-JEF-01C1 & 1,49 & 9,12 & 0,09865 & $0,51125 \pm 21$ & $-27,08$ & $-0,63(\mathrm{t}=2,1 \mathrm{Ga})$ & 2365 \\
\hline TR-JEF-01 & 1,76 & 6,15 & 0,17294 & $0,51266 \pm 7$ & $+0,43$ & $+7,70(\mathrm{t}=2,4 \mathrm{Ga})$ & - \\
\hline
\end{tabular}

Tabela 7 - Valores das razões isotópicas iniciais de Sr e Nd do ortogranulito de composição básica da série toleítica recalculadas para $2,4 G a$.

\begin{tabular}{|c|c|c|c|c|c|c|c|c|}
\hline Amostra & ${ }^{143} \mathrm{Nd} /{ }^{144} \mathrm{Nd}$ & $\begin{array}{l}{ }^{143} \mathrm{Nd} /{ }^{144} \mathrm{Nd} \\
(2,4 \mathrm{Ga})\end{array}$ & $\begin{array}{l}{ }^{143} \mathrm{Nd} /{ }^{144} \mathrm{Nd} \\
(2,4 \mathrm{G} \text { a }) \\
\text { (CHUR) }\end{array}$ & $\varepsilon_{\mathrm{Nd}}(2,4 \mathrm{Ga})$ & ${ }^{87} \mathrm{Sr} /{ }^{86} \mathrm{Sr}$ & $\begin{array}{l}{ }^{87} \mathrm{Sr} /{ }^{86} \mathrm{Sr} \\
(2,4 \mathrm{Ga})\end{array}$ & $\begin{array}{l}{ }^{87} \mathrm{Sr} /{ }^{86} \mathrm{Sr} \\
(2,4 \mathrm{Ga}) \\
\text { (UR) }\end{array}$ & $\begin{array}{l}\varepsilon_{\mathrm{Sr}} \\
(2,4 \mathrm{Ga})\end{array}$ \\
\hline TR-JEF-01 & 0,512660 & 0,509919 & 0,509526 & $+7,70$ & 0,706179 & 0,701648 & 0,7018 & $-1,6$ \\
\hline
\end{tabular}




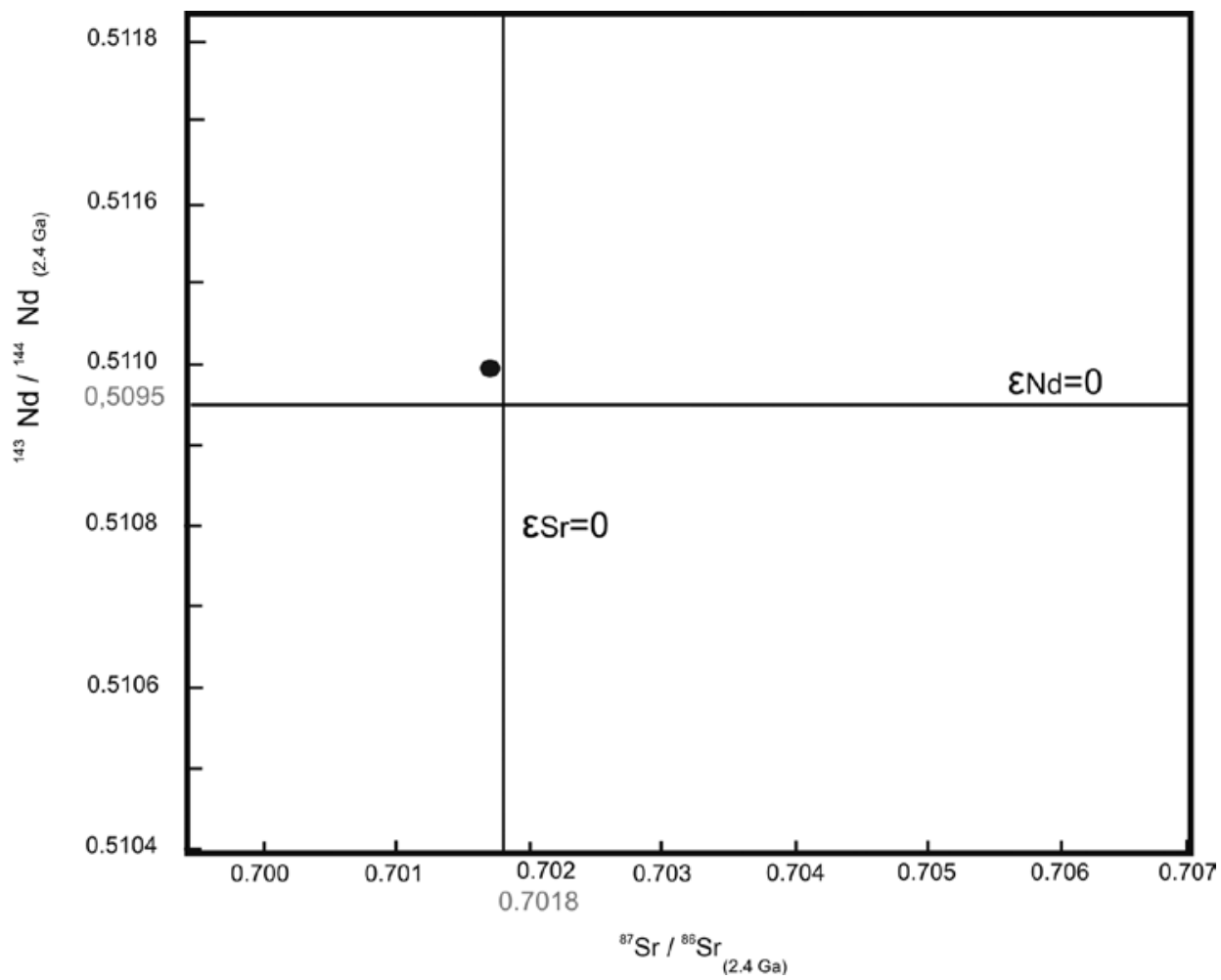

Figura 12 - Diagrama de ${ }^{143} \mathrm{Nd} /{ }^{144} \mathrm{Nd} x^{87} \mathrm{Sr}{ }^{86} \mathrm{Sr}$ para o ortogranulito básico toleitico do Complexo Juiz de Fora na região de Três Rios. Simbologia: amostra TR-JEF-01 (círculo fechado).

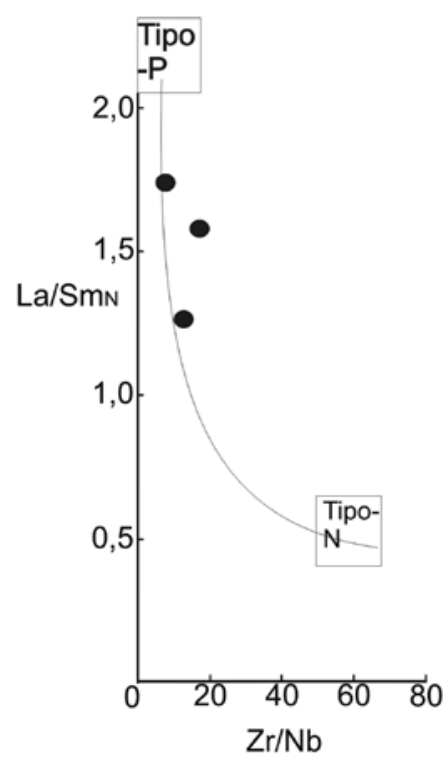

Figura 13 - a) Diagrama de $\mathrm{La} / \mathrm{Sm}_{\mathrm{N}}$ versus $\mathrm{Zr} / \mathrm{Nb}$ indicativo de mistura de magma na geração dos MORBs com a projeção das amostras toleíticas do grupo I da análise litogeoquimica. Fonte: Wilson (1989). protólitos dos ortogranulitos básicos toleíticos investigados a partir de fontes empobrecidas e as características geoquímicas apontam para uma fonte enriquecida, é proposto o modelo de rápida extensão de crosta oceânica (fast-spreading ridges - Allègre et al. 1984) para a geração destes magmas. Nesta situação, haveria suprimento de porções de material mantélico enriquecido para o manto astenosférico empobrecido na geração de basaltos do tipo N-MORB. Para o caso estudado as assinaturas isotópicas indicam que o componente empobrecido foi predominante. Este cenário geodinâmico deve ser o esperado para o Paleoproterozóico (Fig. 14).

CONSIDERAÇÕES FINAIS O estudo litogeoquímico revela que os ortogranulitos/ortognaisses da região de Três Rios podem ser agrupados em 4 séries magmáticas: (i) rochas calcioalcalinas de alto-K; (ii) calcioalcalinas de médio-K (iii) toléticas; e (iv) alcalinas.

Os ortogranulitos/ortognaisses da série calcioalcalina representam rochas de arco vulcânico ou arco magmático. Os ortogranulitos/ortoanfibolitos básicos da série toleítica foram definidos como tendo protólitos em basaltos do tipo intraplaca (oceânicos ou continentais) e em basaltos do tipo E-MORB. O ortogranulito básico da série alcalina, que é representada por uma única amostra, tem possível protólito relacionado a basaltos alcalinos do tipo intraplaca oceânico.

Pela análise geocronológica U-Pb em zircão (LA-ICPMS), foram obtidas idades paleoproterozóicas 


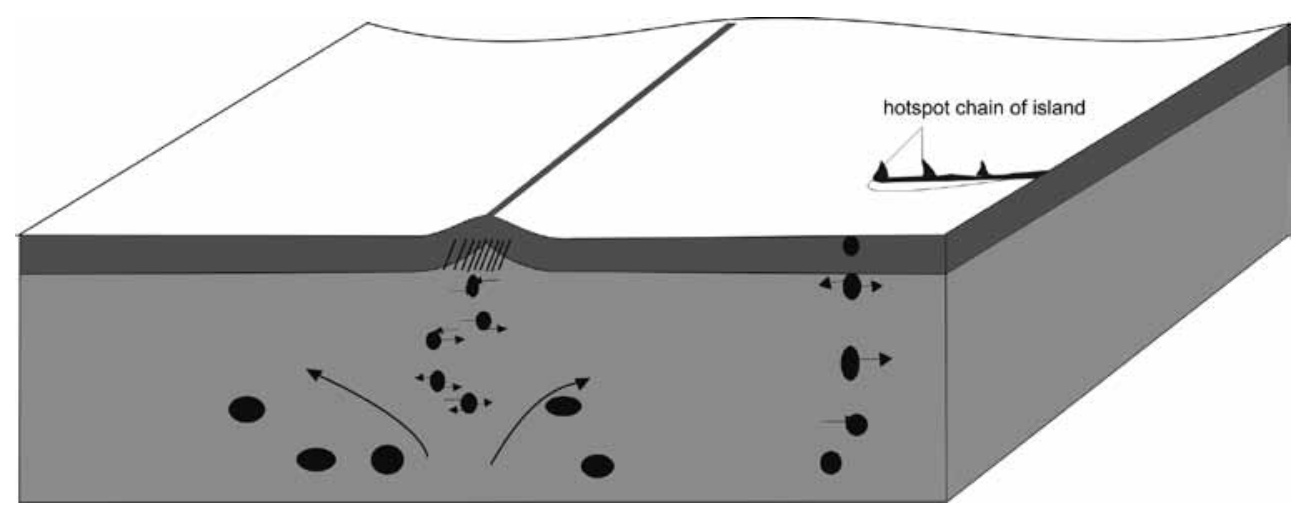

Figura 14 - Modelo: Fast-spreading regime (Allègre et al. 1984). Injeção de blobs do reservatório mantélico enriquecido abaixo da cadeia oceânica. Fonte: Wilson (1991).

para um ortognaisse da série cálcioalcalina de médio-K e duas idades brasilianas $(615,9 \pm 6,4$ Ma e $589,1 \pm 5$ Ma) para um ortogranulito básico toleítico. Essas idades são interpretadas em cada litotipo como idades de cristalização e de metamorfismo, respectivamente.

A idade $\mathrm{T}_{\mathrm{DM}}$ de $\mathrm{Nd}$ calculada para a série de médio-K de 2,37 Ga, juntamente com idade de cristalização obtida para essa mesma associação, revela que seus protólitos foram gerados num arco magmático juvenil durante um evento tectônico paleoproterozóico (Transamazônico) no intervalo de 2,14 a 2,07 Ga (Heilbron et al., 2001). Os valores de $\varepsilon_{\mathrm{Nd}}(-0,63$ e $-0,71)$, fracamente negativos, recalculados para $\mathrm{T}=2,1 \mathrm{Ga}$, indicam a existência de crosta juvenil. Para o conjunto toleítico, não foi possível calcular a idade modelo $\mathrm{T}_{\mathrm{DM}}$ dado o alto valor da razão ${ }^{147} \mathrm{Sm} / 144 \mathrm{Nd}=0,17294$, obtido na amostra selecionada.

Já o conjunto de dados obtidos para os litotipos toleíticos, incluindo dados isotópicos de $\mathrm{Sr}$, indicam geração em ambiente de fundo oceânico (cadeia meso-oceânica), cuja gênese está relacionada a fontes mantélicas empobrecidas $\left(\varepsilon_{\mathrm{Nd}}=+7,7\right.$ e $\left.\varepsilon_{\mathrm{Sr}}=-1,6\right) \mathrm{com}$ contribuição subordinada do manto enriquecido $(\mathrm{La} /$ $\left.\mathrm{Yb}_{\mathrm{N}}>1\right)$ a $c a .2,4 \mathrm{Ga}$, sendo proposto um regime de rápida extensão oceânica.

EVOLUÇÃO GEOLÓGICA PARA O COMPLEXO JUIZ DE FORA O Complexo Juiz de Fora está inserido no contexto geológico do Órogeno Ribeira, como parte do embasamento Paleoproterozóico (Heilbron et al. 2004), que foi retrabalhado durante a Orogenia Neoproterozóica Brasiliano-Pan Africana, a qual resultou na formação da porção ocidental do Paleocontinente Gondwana (Almeida 1977; 1981).

Os dados adquiridos nesta pesquisa em conjunto com os dados disponíveis na literatura permitiram propor o modelo evolutivo para o Complexo a seguir apresentado:

1) Implantação de um rift paleoproterozóico de idade $2,4 \mathrm{Ga}$ em regime de rápido espraiamento oceânico, onde foram gerados basaltos toleíticos do tipo EMORB, diferenciados a partir do manto empobrecido com contribuição subordinada do manto enriquecido.

2) Desenvolvimento de um arco magmático juvenil paleoproterozóico entre 2,14 e 2,07 Ga (Machado et al. 1996a, Heilbron et al. 2001), durante o evento Transamazônico $(2,2$ - 1,8 Ga, Brito Neves, 2004) responsável pela geração de plútons calcioalcalinos de composição granítica a tonalítica.

3) Envolvimento na Orogenia Neoproterozóica Brasiliano-Pan Africana:

a) O primeiro registro geocronológico relacionado a esta orogenia na região de Três Rios foi encontrado em zircões do ortogranulito básico em 615,9 \pm 6,4 $\mathrm{Ma}$ (U-Pb em zircão, LA-ICPMS). Esta idade encontra-se dentro do intervalo de 645-605 Ma, relacionada ao evento referido como pré-M1 por Viana (2008). O segundo registro térmico foi obtido no ortogranulito básico toleítico (LA-ICPMS, U-Pb em zircão $=589,1 \pm$ 5) e relaciona-se ao metamorfismo M1 (estágio de colisão II do Orógeno Ribeira de Heilbron et al. 2004), tendo seu auge em aproximadamente $580 \mathrm{Ma}$ (Machado et al. 1996a, Valladares, 1996). Na literatura esse evento é responsável pelo retrometamorfismo na paragênese de facies granulito do Complexo Juiz de Fora (Heilbron et al. 1995) ao longo de zonas de cisalhamento contemporâneas a este estágio colisional;

b) Desenvolvimento da Zona de Cisalhamento do Rio Paraíba do Sul durante o Estágio de colisão III, relacionado à amalgamação do Terreno Cabo Frio (Heilbron et al. 2004). Segundo dados da literatura, esse estágio de colisão gerou um segundo pulso metamórfico no Órogeno Ribeira (Machado et al. 1996a) de idade entre 535 e $520 \mathrm{Ma}$, que não foi registrado pelos litotipos estudados.

Agradecimentos Os autores agradecem a FAPERJ pela bolsa de mestrado concedida ao primeiro autor durante o desenvolvimento de seu projeto de mestrado no Programa de Pós-graduação em Análise de Bacias e Faixas Móveis da Faculdade de Geologia da UERJ. A CPRM por financiar a projeto, através do PRONAGEO (convênio UERJ/CPRM). Aos técnicos do Laboratório de Geocronologia e Isótopos Radiogênicos (LAGIR), 
Faculdade de Geologia-UERJ pelo apoio na execução das análises isotópicas de Sr e Nd. À Dra . Sílvia Regina de Medeiros pela contribuição na discussão dos resulta- dos isotópicos de $\mathrm{Sr}$ e $\mathrm{Nd}$. Aos dois revisores do artigo por suas sugestões e críticas.

\section{Referências}

Allègre C.J., Hamelin B., Dupré B. 1984. Statistical analysis of isotopic rations in MORB: the mantle blob cluster model and The convective regime of the mantle. Earth Planet. Sci. Lett. 71:71-84.

Almeida F.F.M. de., Hasui Y, Carneiro C.D.R. 1975. Lineamento de Além Paraíba. An. Acad. Brasil. Ciênc., 47(34):575.

Almeida J.C.H. 2000. Zonas de cisalhamento dúctil de alto grau do Médio Vale do Rio Paraíba do Sul. Tese de Doutoramento, IGCE, Universidade Estadual Paulista, 190 p.

Barbosa A.L.M. \& Grossi Sad J.H. 1983. Reinterpretação da "Séries" Juiz de Fora e Paraíba, em Minas Gerais e Rio de Janeiro. In: SBG, Simpósio de Geologia de Minas Gerais, 2, Anais, p.1-15.

Boynton W.R. 1984. Cosmochemistry of the rare earth elements meteorite studies. In: Henderson P. (ed.) Rare Earth Element Geochemistry, Amsterdan, Elsevier, p. 63-114.

Buhn B., Pimentel M.M., Matteine M., Dantas E.L. 2009. High spatial resolution analysis of $\mathrm{Pb}$ and $\mathrm{U}$ isotopes for geochronology by laser ablation muti-collector inductively coupled plasma mass spectrometry (LA-MC-ICO-MS). An. Acad. Brasil. Ciênc., 81(1):99-114.

Cordani U.G., Delhal J., Ledent O. 1973. Orogeneses superposeés dans le Précambrien du Brésil sud-oriental (États du Rio de Janeiro et de Minas Gerais). Rev. Bras. Geoc., 3(1):1-22.

Cox K.G., Bell J.D., Pankhurst R.T. 1979. The interpretation of the igneous rocks. Univ. Chicago Press, 450p.

Cullers R.L., Yeh L.T., Chaudhury S.C.V. 1974. Rare earth elements in Silurian pelitic schists from NW marine. Geochim. Cosmchim. Acta, 38:389-400.

Dayan H. \& Keller J.V.A. 1989. A zona de cisalhamento do rio Paraíba do Sul nas vizinhanças de Três Rios (RJ): uma análise da deformação dada por algumas feições estruturais. Rev. Bras. Geoc., 19(4):494-506.

Delhal J., Ledent D., Cordani U. 1969. Âges $\mathrm{Pb} / \mathrm{U}, \mathrm{Sr} / \mathrm{Rb}$ et $\mathrm{Ar} / \mathrm{K}$ de formations métamorphiques et granitique du SudEst du Brésil (États de Rio de Janeiro et de Minas Gerais). Ann. Soc. Geol. Belg., 92:271-283.

DePaolo D.J. 1981. Trace element and isotopic effects of combined wallrock assimilation and fractional crystallization. Earth Planet. Sci. Lett., 53:189-202.

Dios F.R.B. 1995. Geologia, petrologia e metamorfismo dos terrenos de alto grau da porção norte da Folha Mangaratiba (1:50.000). Rio de Janeiro. Dissertação de Mestrado, Universidade Federal do Rio de Janeiro. 119p.

Duarte B.P. 1998. Evolução tectônica dos ortognaisses do Complexo Juiz de Fora e Mantiqueira na região de Juiz de Fora, M.G.: Geologia, petrologica e geoquímica. Tese de Doutoramento, Instituto de Geociências, Universidade de São Paulo, 284 p.

Duarte B.P. \& Valente S.C. 1999. Modelamento Petrogenético para as Rochas do Complexo Juiz de Fora, Setor Central da Faixa Ribeira. In: SBGq, Congresso de Geoquímica dos Países de Língua Portuguesa, 5, e Congresso Brasileiro de Geoquímica, 7, Porto Seguro, BA, Boletim de Resumos Expandidos, p. 488-491.

Duarte B.P., Figueiredo M.C.H., Campos Neto M., Heilbron M. 1997. Geochemistry of the Granulite Fácies Orthogneisses of Juiz de Fora Complex, Central Segment of Ribeira Belt, Southeastern Brazil. Rev. Bras. Geoc., 27(1):67-82.

Duarte B.P., Heilbron M., Campos Neto M.C. 2000. Granulite/Charnockite from the Juiz de Fora Domain, Central Segment of the Brasiliano-Pan-African Ribeira Belt. Rev. Bras. Geoc., 30(3):358-362.

Ebert H. 1955. Pesquisas na parte sudeste do Estado de Minas Gerais. Relatório Anual do Diretor. Rio de Janeiro, DNPM, DGM, p. 62-81.

Ebert H. 1968. Ocorrência de fácies granulítica no sul de Minas Gerais e regiões adjacentes, em dependência da estrutura orogênica: hipóteses sobre sua origem. Anais Acad. Bras. Ciênc., 40(Supl.):215-229.

Fernandes André J.L. 2009. O Complexo Juiz de Fora na região de Três Rios (RJ): litogeoquímica, geocronologia $\mathrm{U}-\mathrm{Pb}$ (LA-ICPMS) e geoquímica isotópica de $\mathrm{Nd}$. Dissertação de Mestrado. Faculdade de Geologia, Universidade do Estado do Rio e Janeiro, 134 p.

Fischel D.P., Pimentel M.M., Fuck R.A., Costa A.G., Rosiere C.A. 1998. Geology and Sm-Nd Isotopic data for the Mantiqueira and Juiz de Fora Complexes (Ribeira Belt) The Abrecampo-Manhaçú Region, Minas Gerais, Brazil. In: Intern. Conf. Bas. Tect. Brazil, 14th., Abstracts, p.2123.

Grossi Sad J.H. \& Barbosa L.M. 1985. A origem dos charnockitos e rochas afins da região do médio Paraíba do Sul, Estado do Rio de Janeiro. Contribuições à Petrologia e à Mineralogia, SBG-Núcleo de Minas Gerais, p. 15-27.

Heilbron M. 1993. Evolução tectono-metamórfica da seção Bom Jardim de Minas-MG - Barra do Piraí-RJ, setor central da Faixa Ribeira. Tese de Doutoramento, Instituto de Geociências, Universidade de São Paulo, 268p.

Heilbron M., Valeriano C.M., Valladares C.S., Machado N. 1995. A orogênese brasiliana no segmento central da Faixa Ribeira, Brasil. Rev. Bras. Geoc., 25(4):249-266.

Heilbron M., Duarte B.P., Nogueira J.R. 1998. The Juiz de Fora Complex of the Central Ribeira Belt, SE Brazil: a Segment of Paleoproterozoic Granulite Crust Thrusted during the Panafrican Orogeny. Journal of Gondwana Research South Africa, 1(3/4):371-381.

Heilbron M., Pedrosa-Soares AC., Campos Neto M.C., Silva L.C., Trouw R.A.J., Janasi V. 2004. A Província Mantiqueira. In: Mantesso-Neto V., Bartorelli A., Dal Ré Carneiro C., e Brito-Neves B.B (eds.) Geologia do Continente Sul-Americano: Evolução da Obra de Fernando Flávio Marques de Almeida. São Paulo, Beca, p. 203-234.

Heilbron M., Machado N., Duarte B.P. 2001. Revealing the Pa- 
leoproterozoic Transamazonian orogen hiding in the Neoproterozoic Ribeira Belt, Se Brazil. In: Geologic Association of Canada Annual Meeting, St. Johns, Newfoundland, Canada, Abstracts, 26:61.

Irvine T.N. \& Baragar W.R.A. 1971. A guide to the chemical classification of the common volcanic rocks. Canadian Journal of Earth Science, 8:523-548.

Kullerud K., Skjerlie K.P., Corfu F., de la Rosa J.D. 2006. The 2.40 Ga Ringvassøy mafic dykes, West Troms Basement Complex, Norway: The concluding act of early Palaeoproterozoic continental breakup Bull. Precambrian Research, 150:183-200.

Le Maitre R.W. 1989. A Classification of Igneous Rocks and Glossary of Terms. Blackwell, Oxford, $193 \mathrm{p}$.

Machado Filho L., Ribeiro M.W., Gonzalez S.R., Schenini C.A., Santos Neto A., Palmeira R.G.B., Pires J.L., Teixeira W., Castro H.E.F. de. 1983. In: RADAMBRASIL. Folhas SF-23/24, Rio de Janeiro/Vitória, 1. Geologia. Rio de Janeiro, MME, 27-304.

Machado N., Valladares C.S., Heilbron M., Valeriano C.M. 1996a. U-Pb geocronology of the central Ribeira Belt (Brazil) and implications for the Brazilian Orogeny. Precambrian Research. 79:347-361.

Machado N., Schrank A., Noce C.M., Gauthier G. 1996b. Ages of detrital zircon from Archean-Paleoproterozoic sequences: implications for Greenstone Belt setting and evolution of a Transamazonian foreland basin in Quadrilátero Ferrífero, southeast Brazil. Earth Planetary Science Letters, 141:259-276.

Maniar P.D. \& Piccoli P.M. 1989. Tectonic discrimination of granitoides. Geological Society of American Bulletin, 101:635-643.

Middlemost E.A.K. 1975. The basalt clan. Earth Sci. Rev., 11:337-64

Middlemost E.A.K. 1985. Magmas and magmatic rocks. London, Longman Press, 266 p.

Muecke G.K., Pride C., Sarkar P. 1979. Rare earth element geochemistry of regional metamorphic rocks. Phys. Chem. Earth, 11:449-464.

Myashiro A. 1974. Volcanic rock series in island arcs and active continental margins. Am. J. Sci. 274(4):321-355.

Nogueira J.R., Choudhuri A., Bello R.M. 2004. Inclusões fluidas e caminhos P-T retrometamórficos em granulitos do Complexo Juiz de Fora. Rev. Bras. Geoc., 34(4):509-520.

Oliveira M.A.F. 1982. Bulk geochemistry of the Paraíba do Sul Granulitic Belt. Rev. Bras. Geoc., 12(1-3):369-374.

Pearce J.A., Harris N.B.W., Tidle A.G. 1984. Trace element discrimination diagramas for the tectonic interpretation of granitic rocks. Journal of Petrology, 25(4):956-983.

Pitcher W.S. 1983. Granite: typology, geological environment and melting relationships. In: Atherton M.P. \& Gribble C.D. (eds.) Migmatites, Melting and Metamorphism. Shiva Publishing Ltd, Cheshire, p. 277-285.

Ragatky D., Tupinambá M., Heilbron M., Duarte B., Valladares C. 1999. New Sm/Nd Isotopic Data From Pre-1.8 Ga Basement Rocks Of Central Ribeira belt, Brazil. Boletim Geologico Minero Argentino, 34:346-348.

Rollinson H. 1993. Using geochemical data; evaluation, presentation, interpretation. Longman Press, London, 352 p.

Silva L.C. da, Armstrong R., Noce C.M., Pimentel M., Pedrosa-Soares A.C., Leite C., Vieira V.S., Paes V.C. 2002. Reavaliação da evolução geológica em terrenos pré-cambrianos brasileiros com base em novos dados U-Pb SHRIMP. Parte II: Orógeno Araçuaí, Cinturão Mineiro e Cráton São Francisco Meridional. Rev. Bras. Geoc., 32(4):513-528.

Streckeisen A. 1976. To each plutonic rocks its proper name. Earth Science Reviews, 12:1-33.

Valeriano C.M., Medeiros S.R., Vaz G.S., Neto C.C.A. 2009. $\mathrm{Sm}-\mathrm{Nd}$ isotope dilution TIMS analyses of BCR-1, AGV-1 and G-2 USGS rock reference materials: first results from the LAGIR Laboratory at UERJ, Rio de Janeiro. In: Igc/ USP, Simpósio 45 Anos de Geocronologia no Brasil, São Paulo, Boletim de Resumos Expandidos, 1:146-148.

Valladares C.S.1996. Evolução geológica do Complexo Paraíba do Sul no segmento central da Faixa Ribeira com base em estudos de geoquímica e de geocronologia $U-P b$. Tese de Doutoramento, Instituto de Geociências, Universidade de São Paulo, 147 p.

Viana S.M. 2008. Evolução geológica do Terreno Paraíba do Sul, Orógeno Ribeira, Sudeste do Brasil, com base em estudos litogeoquímicos e em geocronologia U-Pb (LAICPMS). Tese de Doutoramento. Faculdade de Geologia, Universidade do Estado do Rio e Janeiro, 230 p.

Wilson M. 1991. Igneous Petrogenesis. A global tectonic approach. Londres, Unwin Hyman, 466 p.

Winchester J.A. \& Floyd P.A. 1977. Geochemical discrimination of different magma series and their differentiation products using immobile elements. Chemical Geology, 20:325-343.

Zindler A. \& Hart S. 1986. Chemical geodynamics. Annual Reviews Earth PLanetary Science, 14:93-571.

Manuscrito ID 15206 Submetido em 28 de agosto de 2009 Aceito em 15 de dezembro de 2009. 